\title{
Immune-to-Brain Signaling in Fever The Brain Endothelium as Interface
}

\author{
Elahe Mirrasekhian
}




\title{
Immune-to-Brain Signaling in Fever The Brain Endothelium as Interface
}

\author{
Elahe Mirrasekhian
}


(C) Elahe Mirrasekhian 2020

Cover image by Memitina/ Mental Clarity/ iStock.

Articles have been reprinted with permission of the respective copyright owners.

ISBN: 978-91-7929-819-7

ISSN: 0345-0082

Printed by LiU-Tryck, Linköping, Sweden 2020 
To my parents 


\section{List of papers}

\section{Paper I}

Björk Wilhelms D, Kirilov M, Mirrasekhian E, Eskilsson A, Kugelberg Örtegren U, Klar Ch, Ridder D, Herschman HR, Schwaninger M, Blomqvist A, Engblom D

Deletion of prostaglandin E2 synthesizing enzymes in brain endothelial cells attenuates inflammatory Fever.

J Neurosci. 2014;34(35):11684-90.

\section{Paper II}

Eskilsson A, Mirrasekhian E, Dufour S, Schwaninger M, Engblom D, Blomqvist A

Immune-induced fever is mediated by IL-6 receptors on brain endothelial cells coupled to STAT3dependent induction of brain endothelial prostaglandin synthesis.

J Neurosci. 2014;34(48):15957-61.

\section{Paper III}

Mirrasekhian E, Nilsson JLÅ, Shionoya K, Blomgren A, Zygmunt PM, Engblom D, Högestätt ED, Blomqvist A.

The antipyretic effect of paracetamol occurs independent of transient receptor potential ankyrin 1mediated hypothermia and is associated with prostaglandin inhibition in the brain.

FASEB J. 2018;32(10):5751-5759. 


\section{Contents}

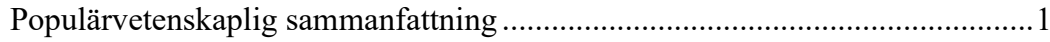

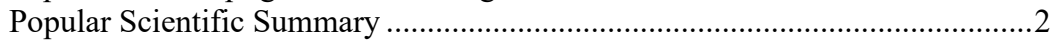

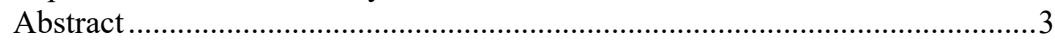

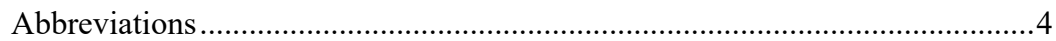

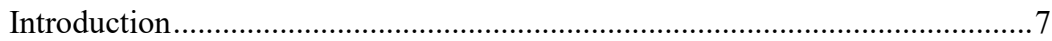

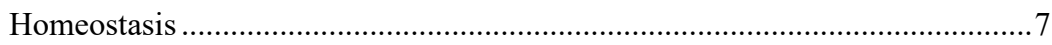

Homeostasis by the nervous system ............................................. 8

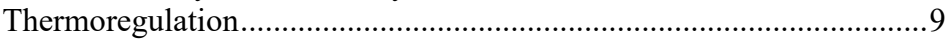

Homeostasis by the immune system ............................................... 12

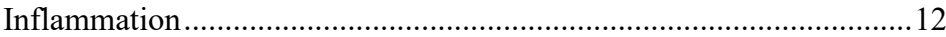

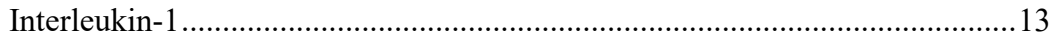

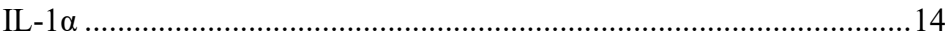

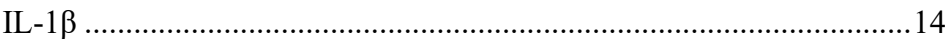

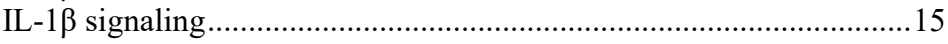

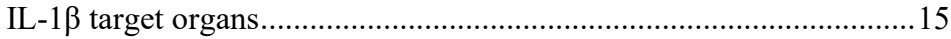

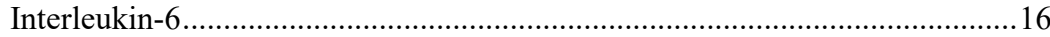

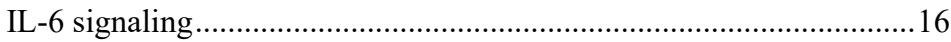

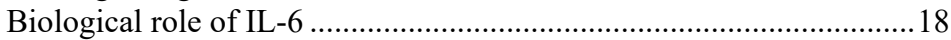

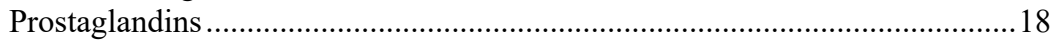

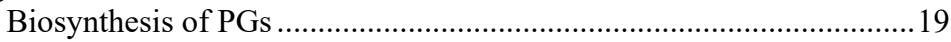

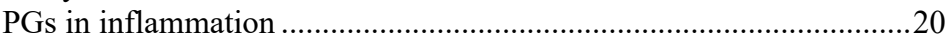

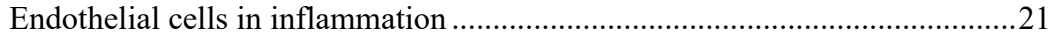

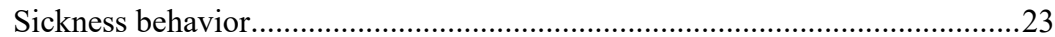

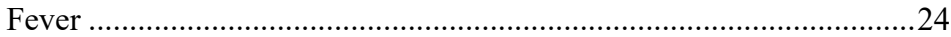

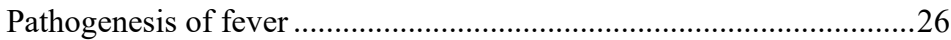

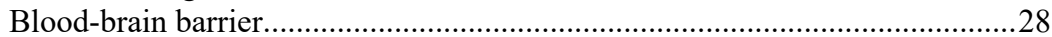

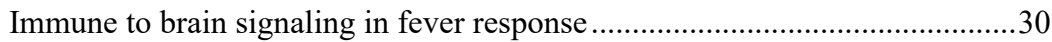

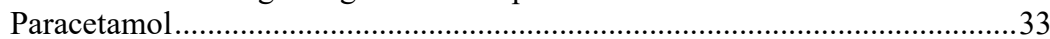

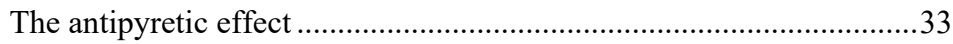

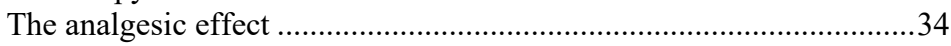

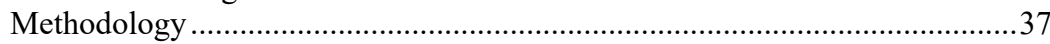

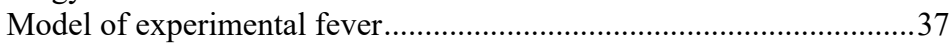

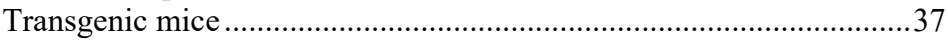

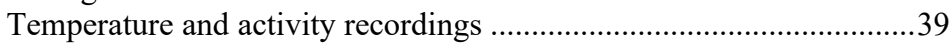

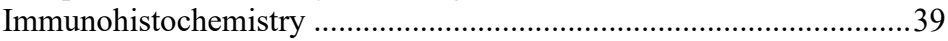

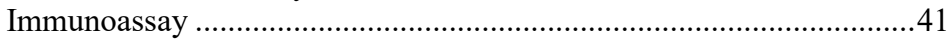

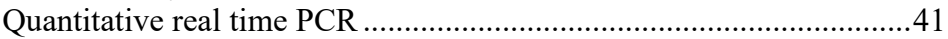

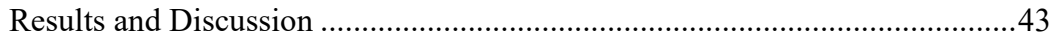

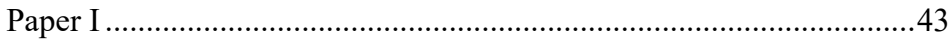

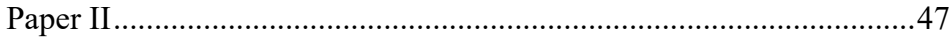

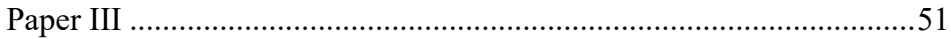

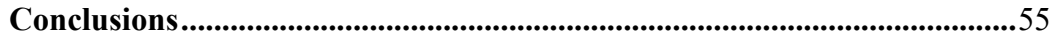

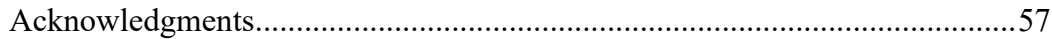

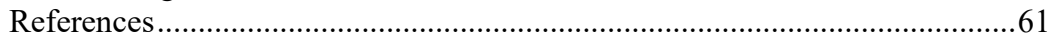





\section{Populärvetenskaplig sammanfattning}

Immunsystemet skyddar kroppen mot farliga mikroorganismer. Då immuncellerna stöter på mikroorganismer svarar de bland annat genom att utsöndra signalämnen som kallas cytokiner. Dessa cytokiner verkar lokalt men kan också nå blodcirkulationen och utlösa inflammationssymptom som exempelvis feber. För febersvaret vet man att de två cytokinerna interleukin-1 och interleukin-6 är viktiga. Feber, som innebär en höjning av kroppstemperaturen, utlöses av hjärnan. Hjärnan är skyddad från blodet av den så kallade blodhjärnbarriären. Denna barriär utgörs av kärlväggen i hjärnans kärl och tillåter inte passage av molekyler som är så stora som cytokiner är. Det har därför varit oklart hur hjärnan kan svara på de cirkulerande cytokinerna och utlösa feber.

Man har länge vetat att bildning av det inflammatoriska ämnet prostaglandin $E_{2}$ i hjärnan är viktigt för febersvaret. Det har dock varit oklart i vilken celltyp prostaglandinbildningen sker och hur denna utlöses av de cirkulerande cytokinerna. För att ta reda på detta studerade vi febersvaret $\mathrm{i}$ genetiskt manipulerade möss som saknade förmåga att bilda prostaglandin $\mathrm{E}_{2} \mathrm{i}$ hjärnans endotelceller eller saknade interleukin-6 receptorer i samma celler. Våra resultat visar att prostaglandinbildning i hjärnans endotelceller behövs för ett normalt febersvar och att bindning av cirkulerande interleukin-6 till receptorer på hjärnans endotelceller leder till prostaglandinbildning och därmed till feber. Sammantaget visar detta att hjärnans endotelceller är en viktig kontaktyta mellan immunsystemet och hjärnan och att signalering i dessa celler är centralt för den signalväg som utlöser feber.

Feber är ofta ett gynnsamt svar på infektion eftersom det begränsar vissa mikroorganismers tillväxt och förstärker immuncellernas funktion. Ibland kan dock feber vara skadligt, i synnerhet om den är hög eller långvarig. Paracetamol är ett läkemedel som ofta används för att dämpa feber. Höga doser av paracetamol leder även till en sänkt basal kroppstemperatur, så kallad hypotermi. En tidigare studie visar att paracetamol utlöser hypotermi genom att binda till en molekyl kallad Trpa1. Vi undersökte huruvida paracetamol även hämmar feber genom att binda till Trpa1. Våra resultat visar att paracetamol inte hämmar feber genom att hämma Trpa1 utan genom att hämma prostaglandinbildning i hjärnan. 


\section{Popular Scientific Summary}

The immune system protects the body against pathogens. This process includes recognition of invading pathogens by immune cells which leads to their activation and release of blood-borne hormones that are called cytokines. Cytokines such as interleukin-1 and interleukin- 6 are potent mediators that induce symptoms of systemic inflammation such as fever. Fever, which is the elevation of body temperature, is regulated by the brain. The brain, on the other hand, is protected by the vessel walls that acts as a barrier and do not allow the passage of substances into the brain tissue. These vessels are lined by brain endothelial cells. It is not clear how cytokines such as interleukin-6 can communicate to the brain and generate fever.

Production of the inflammatory mediator prostaglandin $E_{2}$ in the brain is necessary for the generation of fever. However, it is not known which cell types in the brain produce the prostaglandin $E_{2}$ that is necessary for fever. To address these questions, we injected an inflammatory substance to mice as an experimental model for fever. Mice were genetically manipulated to lack production of prostaglandin $E_{2}$ in the brain endothelial cells or lack the receptor that binds interleukin-6 in different cell types including the brain endothelial cells. Our results showed that the brain endothelial cells are the source of prostaglandin $E_{2}$ that is necessary for fever. Moreover, we showed interleukin- 6 acting on the brain endothelial cells is necessary for the subsequent production of prostaglandin $\mathrm{E}_{2}$ by these cells and consequently also for fever. Taken together, these findings introduce the brain endothelial cells as interface between the immune system and the brain for the generation of fever.

Fever is beneficial to some extent because it restricts the growth of pathogens and increase the activation of immune cells to fight infection. But it can be detrimental if the body temperature remains high for longer period or exceed $41^{\circ} \mathrm{C}$. Therefore, antipyretic drugs such as paracetamol are used to control the body temperature. However, higher doses of paracetamol can lower the body temperature, so-called hypothermia. Studies in mice showed that hypothermia is dependent on the activation of a sensory molecule in cells which is called transient receptor potential ankyrin 1 . We tested if this receptor is necessary for the antipyretic effect of paracetamol. Our results showed that the antipyretic mechanism of paracetamol is not similar to the hypothermic mechanism. We showed that the antipyretic action of paracetamol is mediated through decreasing the production of prostaglandin $E_{2}$ in the brain. 


\section{Abstract}

Fever is a brain-regulated elevation of body temperature that occurs in response to infectious and non-infectious stimuli. During inflammatory episodes, circulating cytokines that are released by activated immune cells, trigger the induction of cyclooxygenase (COX)-2 in the ventromedial preoptic area of the hypothalamus (the thermoregulation center). COX-2dependent-prostaglandin ( $\mathrm{PG}) \mathrm{E}_{2}$ synthesis is essential for the generation of fever and upon an immune challenge, it is induced in several cells within the brain including the brain endothelial cells and perivascular macrophages. However, due to lack of experimental models with cell type-specific modulation of $\mathrm{PGE}_{2}$ synthesizing enzymes, the cellular source of pyrogenic $\mathrm{PGE}_{2}$ and its induction mechanism(s) remained obscure. Using such technology, we showed that the brain endothelium is the cellular source of pyrogenic $\mathrm{PGE}_{2}$ and that activation of brain endothelial IL-6 receptors by circulating IL-6 is critical for the PGE 2 induction.

Inhibition of $\mathrm{PGE}_{2}$ synthesis is assumed to be the mode of action of many antipyretic drugs, possibly including paracetamol. Given that paracetamol at a high dose has been shown to induce hypothermia by activation of the transient receptor potential ankyrin 1 (TRPA1) ion channel, we examined whether the antipyretic effect of paracetamol is also TRPA1 dependent. Our findings revealed that the antipyretic effect of paracetamol is independent of TRPA1 and associated with inhibition of the $\mathrm{PGE}_{2}$ synthesis in the brain.

This thesis provides new insight into the molecular mechanism behind the febrile response in which the peripheral circulating IL-6 communicates with the brain by induction of pyrogenic $\mathrm{PGE}_{2}$ in the brain endothelium. It also demonstrates that the antipyretic effect of paracetamol is exerted by inhibition of the $\mathrm{PGE}_{2}$ synthesis in the brain. 


\section{Abbreviations}

\begin{tabular}{|c|c|}
\hline АCTH & Adrenocorticotrophic hormone \\
\hline AM404 & $\mathrm{N}$-arachidonoylphenolamine \\
\hline AP-1 & Activator protein-1 \\
\hline BAT & Brown adipose tissue \\
\hline BBB & Blood-brain barrier \\
\hline BM & Basement membrane \\
\hline BSF-2 & B-cell stimulatory factor 2 \\
\hline CB & Cannabinoid \\
\hline cDNA & Complementary DNA \\
\hline CLR & C-type lectin receptors \\
\hline CNS & Central nervous system \\
\hline $\operatorname{cox}$ & Cyclooxygenase \\
\hline cPGES & Cytosolic prostaglandin E synthase \\
\hline $\mathrm{CRH}$ & Corticotropin-releasing hormone \\
\hline CRP & C-reactive protein \\
\hline $\mathrm{Ct}$ & Cycle threshold \\
\hline CVC & Cutaneous vasoconstriction \\
\hline CVOs & Circumventricular organs \\
\hline DAB & Diaminobenzidine \\
\hline DAMPs & Damage-associated molecular patterns \\
\hline $\mathrm{DH}$ & Dorsal horn \\
\hline $\mathrm{DMH}$ & Dorsal medial hypothalamus \\
\hline DRG & Dorsal root ganglia \\
\hline ELISA & Enzyme-linked immunosorbent assay \\
\hline EP & Subtypes E prostanoid receptors \\
\hline ER & Estrogen receptor \\
\hline FAAH & Fatty acid amide hydrolase \\
\hline gp130 & Glycoprotein 130 \\
\hline HPA & Hypothalamic-pituitary-adrenal \\
\hline HSF & Hepatocyte-stimulating factor \\
\hline ICAM & Intracellular adhesion molecules \\
\hline IFN & Interferon \\
\hline IKK & Inhibitory kappa B kinase complex \\
\hline IL & Interleukin \\
\hline IRAKs & IL-1R-activated protein kinases \\
\hline IKB & Inhibitory kappa B \\
\hline JAK & Janus tyrosine kinases \\
\hline JNK & C-Jun $\mathrm{N}$-terminal kinase \\
\hline KO & Knockout \\
\hline LAF & Lymphocyte activator factor \\
\hline LPB & Lateral parabrachial nucleus \\
\hline LPS & Lipopolysaccharide \\
\hline MAPK & Mitogen activated-protein kinase \\
\hline MCP1 & Monocyte chemoattractant protein 1 \\
\hline $\mathrm{MHC}$ & Major histocompatibility complex \\
\hline $\mathrm{MnPO}$ & Median preoptic nucleus \\
\hline MPGES & Microsomal prostaglandin E synthase \\
\hline MPO & Medial preoptic nucleus \\
\hline MyD88 & Myeloid differentiation primary response gene 88 \\
\hline NAC & $\mathrm{N}$-acetylcysteine \\
\hline NAPQI & $\mathrm{N}$-acetyl-p-benzo-quinone imine \\
\hline NFKB & Nuclear factor kappa-light-chain-enhancer of activated B cells \\
\hline NLR & NOD-like receptors \\
\hline
\end{tabular}




$\begin{array}{ll}\text { NO } & \text { Nitric oxide } \\ \text { NSAIDs } & \text { Non-steroidal anti-inflammatory drugs } \\ \text { NVU } & \text { Neurovascular unit } \\ \text { OVLT } & \text { Organum vasculosum of the lamina terminalis } \\ \text { PAF } & \text { Platelet-activating factor } \\ \text { PAMPs } & \text { Pathogen-associated molecular patterns } \\ \text { PG } & \text { Prostaglandin } \\ \text { POA } & \text { Preoptic area } \\ \text { PRRs } & \text { Pattern recognition receptors } \\ \text { PTGS } & \text { Prostaglandin-endoperoxide synthase } \\ \text { PVMs } & \text { Perivascular macrophages } \\ \text { ROS } & \text { Reactive oxygen species } \\ \text { rRPA } & \text { Rostral raphe pallidus } \\ \text { SHP2 } & \text { Src homology protein 2 tyrosine phosphatase 2 } \\ \text { SOCS } & \text { Suppressor of cytokine signaling } \\ \text { STAT } & \text { Signal transducer and activator of transcription } \\ \text { TAK1 } & \text { Transforming growth factor } \beta \text { - activated kinase 1 } \\ \text { TIR } & \text { Toll-like/Interleukin receptor like } \\ \text { TLR } & \text { Toll-like receptor } \\ \text { TNF } & \text { Tumor necrosis factor } \\ \text { TRAF6 } & \text { Tumor necrosis factor receptor associated factor 6 } \\ \text { TRP } & \text { Transient receptor potential } \\ \text { TRPA } & \text { Transient receptor potential ankyrin } \\ \text { TRPM } & \text { Transient receptor potential melastatin } \\ \text { TRPV } & \text { Transient receptor potential vanilloid } \\ \text { TX } & \text { Thromboxane } \\ \text { WT } & \text { Wild type } \\ & \\ & \end{array}$




\section{Homeostasis}

Biological systems from human body to living organisms tend to maintain a steady physiological and chemical states for survival. The mechanisms help to maintain a steady internal environment was first named in the 1870s by a French physiologist Claude Bernard, "the milieu intérieur". Later in the 1920s, American biologist Walter Cannon coined the term of "homeostasis" by which the body regulates and adjusts the function of the various internal systems, subjected to internal or external challenges, from an emotional stress to tissue injury or pathogens invasion ${ }^{1}$.

Several physiological systems such as the central nervous system (CNS), endocrine and immune systems contribute in an homeostatic regulation ${ }^{2}$. While the nervous system controls heart rate, blood pressure, respiratory rate, electrolyte balance and thermoregulation, the endocrine system instead regulates metabolism and the immune system actively maintains the cellular integrity, tissue repair and protects the body against biotic invasion ${ }^{3}$.

The immune and nervous systems share several properties such as complexity, information handling and widespread coverage over all organs. For an optimal bodily function, an extensive collaboration of the immune, endocrine, and nervous systems needs to be reached. Any impairment in the function of these systems leads to the homeostatic failure and ultimately causing a condition that is called "disease".

Physiological and psychogenic stressors are the typical examples of homeostatic disturbances where a coordinated activation of the neuroendocrine and autonomic systems is involved to maintain the homeostatic state. This complex body reaction is called "stress response" which manifests by the activation of the hypothalamic-pituitary-adrenal (HPA) axis. Briefly, the stressors trigger the secretion of corticotropin-releasing hormone $(\mathrm{CRH})$ from hypothalamus in the CNS which in turn induces the secretion of adrenocorticotrophic hormone (ACTH) by the pituitary gland. ACTH then induces the production of glucocorticoid hormones from the adrenal glands (the endocrine system) and elevates the metabolic rate to provide more energy for the organs involved in the stress-challenged condition ${ }^{4}$. Long-term stress, however, results in impairment and even suppression of the immune system, promoting susceptibility to infections and inflammation ${ }^{5}$. 


\section{Homeostasis and the nervous system}

From an evolutionary point of view, the nervous system is known as a main sensory system of the human body by which environmental information as physical stimuli are sensed and interpreted as sight, touch, sound, smell, and taste. However, the function of the nervous system is not merely limited to the processing of the environmental stimuli. Internal and external information are constantly received by the sensory structures and ascended to the integration site of the nervous system, CNS, by which appropriate somatic (voluntary) and autonomic (involuntary) responses are generated to maintain a homeostatic balance ${ }^{6}$. The constant monitoring of internal and external challenges is an essential characteristic of homeostatic regulation by the nervous system.

Body temperature is one of the critical homeostatic parameters to ensure optimal physiological function. Although, the body temperature is constantly influenced externally by environmental temperature and internally by hormones, metabolism, exercise, and infection, it is rigidly regulated within an accepted range known as temperature "set point"?

The dynamic regulatory mechanism to maintain this homeostatic set point is called "thermoregulation". In fact, in response to any external or internal thermal deviations, the nervous system employs appropriate effector mechanisms to achieve a fine balance between heat gain and heat $\operatorname{loss}^{8,9}$. Considering the endothermic nature of human body, the core temperature heat is primarily gained from metabolism and mechanical muscular contraction. The heat produced is then either conserved by vasoconstriction (vasomotor changes to restrict peripheral blood flow) or dissipated through a process of evaporation (e.g. sweating), radiation (e.g. infrared emission from skin), conduction and/or convection (heat transfer based on thermal gradients) ${ }^{10}$. 


\section{Thermoregulation}

Thermoregulatory effector mechanisms are fine-tuned by the hypothalamic neurons to defend the core temperature against cold or heat, through coordination of physiological and behavioral responses $^{8}$. The physiological responses, termed as cold and heat-defenses, are mediated by the autonomic nervous system. The mechanisms of physiological thermal defenses include skin vasodilation and sweating in heat-defensive responses, whereas vasoconstriction and thermogenesis are mechanisms of the cold-defensive responses. Two types of thermogenesis have been identified: shivering thermogenesis in the skeletal muscles and non-shivering thermogenesis in brown adipose tissue (BAT) ${ }^{11}$. The thermoregulatory behaviors, contrary to the physiological responses, are voluntary (e.g. cold or heat avoidance responses or postural changes) $)^{12}$.

The neural pathway of physiological thermoeffector responses consists of three components: sensory afferent signaling, central integration and efferent "effector" signaling ${ }^{13}$.

Thermal sensation by thermosensitive receptors or thermosensory neurons, distributed in several areas of the body including periphery (i.e. skin), visceral tissues (i.e. abdomen and spinal cord) and within the brain in many areas particularly in the preoptic area (POA) of the hypothalamus, is the initial phase of somatosensory afferent pathway ${ }^{14}$. Thermosensory elements of these neurons belong to a family of cations channels known as transient receptor potential (TRP) that sense a broad physiological range of temperature from noxious cold to noxious heat ${ }^{15}$.

From the known-TRP channels, 11 members are identified as thermoTRP. For example, TRPA1 (member 1 of the subfamily A (ankyrin)) and TRPM8 (member 8 of the subfamily M (melastatin)) are known to sense the noxious and innocuous cold, respectively ${ }^{16,17}$. TRPV3 and TRPV4 (members 3 and 4 of the subfamily V(vanilloid)) mediate innocuous warm sensation ${ }^{18 \text {, }}$ ${ }^{19}$, whereas TRPV1 and TRPV2 are known to sense noxious and burning heat ${ }^{20,21}$.

While most of the visceral and peripheral thermoreceptors are cold-sensitive ${ }^{22}$, the central thermoreceptors are mainly warm-sensitive ${ }^{23}$. This could be explained by the fact that constant heat produced from metabolism in endothermic animals including human needs to be highly restricted. Furthermore, the core overheating is considered a greater risk for survival, because only a few degrees higher temperature than homeostatic set point results in proteins denaturation, disruption of cellular function and ultimately cellular death. 
The thermal signals from somatosensory afferent neurons in skin and viscera are transmitted to the primary sensory neurons in the dorsal root ganglia (DRG) and further to the somatosensory neurons in the dorsal horn $(\mathrm{DH})^{24,25}$. The thermal signals are encoded by either cold or warm-sensory DH neurons activated by innocuous skin cooling or warming. The glutamatergic projections of DH thermosensory neurons via spinothalamocortical and spinoparabrachiaiopreoptic pathways mediate perception and feedforward thermoregulatory responses, respectively ${ }^{26,27}$.

Perception or discrimination of temperature is coordinated by the glutamatergic projection of the cold and warm-sensory DH neurons to the primary somatosensory neurons in the insular cortex via thalamic nucleus ${ }^{28,29,30}$. Whereas glutamatergic projections of these DH neurons to the median preoptic nucleus (MnPO) via activation of the lateral parabrachial nucleus (LPB) mediates the physiological thermoregulatory responses ${ }^{31}$. The type of physiological response (cold or heat defenses) to regulate the core body temperature is determined by activation of distinct subregions of the LPB, known as "sensory mediating regions". Activation of the external lateral region of LPB by the glutamatergic input from cold-sensory DH neurons initiates cold-defense responses, while the dorsal LPB activation by warm-sensory-projecting DH neurons drives heat-defense responses ${ }^{27,32}$.

The ascending thermosensory signals transmitted from the LPB-projecting neurons are relayed to the warm and cold-sensitive MnPO neurons in the POA of hypothalamus ${ }^{33}$. The MnPO is the thermal integration center that receive massive thermal afferent signals from skin and viscera as well as signals represented by the local thermosensitive POA neurons (Fig. 1A) ${ }^{23,34}$, 35 .

The thermosensitive MnPO neurons that served as key regulator for the body temperature, are either glutamatergic or GABAergic which respectively inhibit or activate warm-sensitive neurons in the medial preoptic nucleus (MPO), a subregion of the $\mathrm{POA}^{23,36}$. It should be noted that considering the MnPO and MPO as two distinct subregions is still debated.

Although, the MPO neurons are believed to be GABAergic and provide inhibitory tonic discharge at thermoneutral temperature, recent studies demonstrated glutamatergic nature of these warm-sensitive neurons ${ }^{37,} 38,39$. In any case, the thermoregulatory efferent neural pathways are mediated by the intra-POA neurons by sending command signals to peripheral effectors. 
GABAergic projections to the MPO neurons in response to cold reduces their inhibitory output to the dorsal medial hypothalamus (DMH) and rostral raphe pallidus (rRPA) in the brain stem ${ }^{40}$. Reduced inhibitory projections to the rRPA directly or via DMH activates preganglionic neurons in the spinal cord and further sympathetic ganglia which controls effector responses such as sympathetic cutaneous vasoconstriction (CVC) and BAT thermogenesis. Disinhibition of rRPA neurons also activates the ventral horn anterior motoneurons which control the shivering thermogenesis in the skeletal muscles. CVC, shivering, and BAT thermogenesis are then activated to reserve body temperature and induce heat production ${ }^{41,42,43}$.
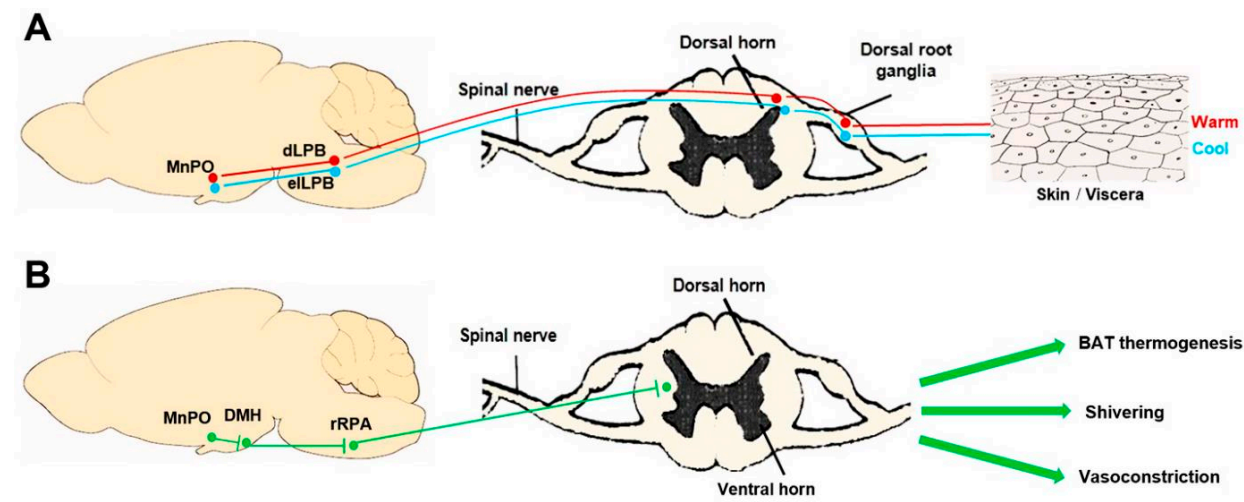

Figure 1. The neural pathway of physiological thermoeffector responses. A) Sensory afferent signaling pathway. B) Efferent "effector" signaling pathway.

In an opposite way, glutamatergic projection to the MPO neurons in response to heat activates their inhibitory output to the DMH and rRPA. Inhibitory projection to the preganglionic neurons in the spinal cord and sympathetic ganglia attenuates the sympathetic nerve activity resulting in inhibition of CVC and BAT thermogenesis (Fig. 1B) $)^{27,41}$. 


\section{Homeostasis and the immune system}

The ability of immune system to respond to interior and exterior environmental challenges, similar to the nervous system, entitles it as an arm of the homeostatic regulation system ${ }^{44}$. In biophylactic point of view, the immune system protects the body from external invasions by foreign organisms, whereas the unique property of the immune system to monitor tissue integrity, bone homeostasis, metabolic control and organ functionality introduces it as a sensory system to regulate homeostasis in other ways ${ }^{45}$.

\section{Inflammation}

Immune function depends on a series of events from recognition of the damaging agent, activation of immune cells, preventing ongoing tissue damage and eventually initiation of tissue repair. The occurrence of these events leads to local reactions in the affected tissue, known as "inflammation".

Sensing the presence of damaging factors is the initial phase of inflammatory response. A wide group of pathogens such as lipopolysaccharide (LPS) of Gram-negative bacteria, mannans of yeast, glycolipids of mycobacteria, lipoteichoic acids of Gram-positive bacteria and doublestranded RNAs of viruses share a common molecular array known as pathogen-associated molecular patterns (PAMPs) ${ }^{46,47}$. Moreover, cells undergoing programed cell death (apoptosis) due to the tissue damage or necrotic cells release another type of molecular pattern known as damage-associated molecular patterns (DAMPs) or alarmins ${ }^{48}$. PAMPs and DAMPs are recognized by immune cells which are equipped with pattern recognition receptors (PRRs) either as humoral proteins in the blood stream or signaling receptors on cells. Two different types of signaling PRRs have been identified: transmembrane form such as Toll-like (TLR) and C-type lectin receptors (CLR) or cytoplasmic proteins such as RIG-I-like and NOD-like receptors $(\mathrm{NLR})^{49}$.

The recognition of PAMPs or DAMPs by either soluble or signaling type of PRRs in immune cells triggers a set of immediate reactions in the site of inflammation, known as "acute phase response" ${ }^{90}$. Blood monocytes and tissue macrophages are the most prominent cells in the initiation of the acute phase response. Following activation of macrophages and monocytes, an array of intracellular signaling in these cells results in the signal transduction of modules 
including nuclear factor kappa-light-chain-enhancer of activated B cells (NF- $\kappa \mathrm{B}$ ), activator protein-1 (AP-1), and mitogen-activated protein kinase (MAPK) ${ }^{51}$. These signal transduction pathways, in turn, drive the production of many inflammatory genes such as interleukin (IL)1, IL-6 and tumor necrosis factor (TNF)- $\alpha$ by monocytes/macrophages, chemokines by neutrophils and inflammatory proteins synthesized by hepatocytes ${ }^{52}$.

C-reactive protein (CRP) is an example of an inflammatory protein which is also considered to be a humoral PRRs ${ }^{53}$. In response to the inflammation, it is produced by the hepatocytes in the liver in a concentration-dependent manner and presents in the bloodstream as well as interstitial fluids. CRP is a useful indicator to search for etiology and to determine the extent of the existing disease in clinical setting.

The signal transduction of inflammatory genes in immune cells activates the microbicidal and proinflammatory response by which the invading pathogens are eventually eliminated, or the infected cells undergo apoptosis. Apoptosis of the infected cells is planned to restrict the tissue damage by inflammation. Some acute phase proteins have also been shown to participate in tissue repair and homeostasis.

\section{Interleukin-1}

The discovery of IL-1 was coincided with investigations into the nature of pyrogenic proteins which at the time was believed to be released from leukocytes ${ }^{54}$. Later, purification of peripheral blood monocytes by Dinarello and his colleagues led to the identification of IL-1 as pyrogenic protein ${ }^{55}$. Extensive structural studies on IL-1 elucidated that IL-1 is member of a cytokine superfamily, consisting of 11 members, Most of these are proinflammatory, but some of them also have anti-inflammatory properties ${ }^{56}$. Among all, IL-1 $\alpha$ and IL-1 $\beta$ are the best characterized proinflammatory cytokines that bind to the same receptor while encoded by distinct genes. 
IL-1 $\alpha$ is constitutively expressed in epithelial cell of the gastrointestinal tract, lung, kidney, and liver as well as endothelial cells ${ }^{57,58}$. The function of IL-1 $\alpha$ depends on the cellular localization of its precursor, meaning the nuclear or cytosolic localization of IL-1 $\alpha$ precursors make it as transcription or signal transducer factors, respectively ${ }^{59,60}$. Given the cellular localization of its precursor, IL-1 $\alpha$ has been known as dual-function cytokine ${ }^{56}$. In homeostatic regulation with respect to proapoptotic signals from dead cells, the IL-1 $\alpha$ precursor acts as transcription factor in which by binding to the nucleus prohibits the induction of inflammatory cascade. Whereas in response to necrotic signals e.g. ischemic condition (tumor necrosis, myocardial infarction or stroke), the IL-1 $\alpha$ precursor migrates from the nucleus to the cytosol where it binds to its cell membrane receptor and initiates the signal transduction ${ }^{61}$.

IL- $1 \alpha$ is not only present inside of abovementioned cell types, it is also expressed on the surface of blood monocytes and type B lymphocytes ${ }^{62}$. This membrane type of IL- $1 \alpha$ plays a critical role in inflammatory responses, particularly due to its involvement in interferon (IFN)- $\delta$ activities $^{63}$. IL-1 $\alpha$ is known as an "alarmin", meaning that it acts as DAMPs and mediates the initial phase of so-called "sterile inflammation", a condition that arises during noninfectious inflammations such as burn or trauma ${ }^{61}$.

\section{$I L-1 \beta$}

Unlike the IL-1 $\alpha$ precursor that shuttles between the nucleus and cytosol, the IL-1 $\beta$ precursor is merely accumulated in the cytosol. Nearly all microbial products via TLRs signaling, activated complement components, TNF- $\alpha$ and IL- 1 itself, can mediate the induction of IL- $1 \beta$ in blood monocytes, tissue macrophages, dendritic cells, and brain microglia ${ }^{64}$. The IL- $1 \beta$ precursor is biologically inactive and requires an enzymatic cleavage by caspase- 1 from inflammasome, proteinase-3 or elastase from activated neutrophils for conversion to its active form $^{65,66}$. Hence, unlike IL- $1 \alpha$, IL-1 $\beta$ is only processed and secreted under inflammatory conditions. 


\section{IL-1 $\beta$ signaling}

Multiple biological effects of IL-1 $\beta$ are exerted through its interaction with transmembrane receptor complex that consists of IL-1 receptor 1 (IL-1R1) and accessory chain IL-1R3. Similar to TLR, the IL-1R is characterized by two homologous but discrete intracellular Toll/IL-1R like (TIR) domains ${ }^{67}$. Activation of TIR domains trigger assembling of adaptor protein myeloid differentiation primary response gene 88 (MyD88) and subsequently IL-1R-activated protein kinases (IRAKs). Thereafter, TNF receptor associated factor 6 (TRAF6) is recruited to form another complex with transforming growth factor $\beta$ - activated kinase 1 (TAK-1) ${ }^{68}$.

TAK-1/TRAF6 complex in turn allows possibly a parallel degradation of other protein kinases called inhibitory kappa B-kinase complex (IKK) and MAPKs. Degradation of inhibitory kappa $\mathrm{B}(\mathrm{I} \kappa \mathrm{B})$, as IKK complex member, promotes nuclear translocation of NF- $\mathrm{BB}$ and encoding IL6, IL-8, monocyte chemoattractant protein 1 (MCP1) and cyclooxygenase (COX) 2. Degradation of c-Jun N-terminal kinase (JNK) together with p38 from MAPKs pathways, instead result in the nuclear translocation of AP-1 and expression of genes involve in the inflammatory responses ${ }^{68,69,70}$.

\section{IL-1 $\beta$ target organs}

IL-1 $\beta$ is known to orchestrate the innate immune response and inflammation. As a pleiotropic cytokine, it mediates several aspects of an inflammatory response: from local lesion in the initial stage of inflammatory response to the systemic course of inflammation and fever. Il-1 $\beta$ is not only a potent pyrogenic cytokine acting on the brain, it is also a major pathogenic mediator that can indirectly target several other organs ${ }^{64}$.

IL-1 $\beta$ stimulates activation of macrophages that are expert phagocytes and antigen presenting cells in the innate immunity. Activated macrophages then produce other proinflammatory cytokines such as IL-6, TNF- $\alpha$ and IL- $1 \beta$ as well ${ }^{71}$.

IL-1 $\beta$ is also known as lymphocyte activator factor (LAF) together with IL-2. It, therefore, indirectly triggers the adaptive immune responses to resolve inflammation ${ }^{72}$. As mentioned above, IL-1 $\beta$ induces the expression of IL- 8 and MCP-1 which, respectively, recruit more neutrophils and monocytes to the site of inflammation ${ }^{73,74}$. Increased expression of adhesion 
molecules on vascular endothelium is another feature of IL-1 $\beta$ which facilitate the infiltration of abovementioned leukocytes from circulation to the site of inflammation.

In addition, hepatocytes in response to IL-1 $\beta$ synthesize acute phase proteins such as CRP, complement and fibrinogen that act as humoral arm of innate immunity ${ }^{72}$. For example, fibrinogen mediates coagulation and subsequently occlusion in the micro vessels to limit the spread of infection ${ }^{73}$.

Intracellular signaling of IL-1ß/IL-1R1-IL1R2 leads to the upregulation of genes involved in prostaglandins (PGs) synthesis e.g. COX $-2^{75}$. Although, IL-1 $\beta$ was coined as endogenous pyrogen at the time of its discovery ${ }^{54}$, the fever response has later been shown to be dependent on $\mathrm{PGE}_{2}{ }^{76}$, an arachidonic acid-derived hormone that is produced by the activity of COX-2. In fact, many biological activities of IL- $1 \beta$ in the CNS are believed to be mediated by $\mathrm{PGE}_{2}$.

Activation of HPA axis is another biological activity of IL-1 $\beta$ in the brain. Although, it was previously shown that IL- $1 \beta$ directly activates the pituitary neurons to increase the release of $\mathrm{ACTH}^{77}$, Vasilache and collaborates using LPS-induced inflammation model have shown that inflammatory $\mathrm{PGE}_{2}$ is responsible for the activation of HPA axis ${ }^{78}$.

\section{Interleukin-6}

IL-6 belongs to a superfamily of cytokines with 9 members. As another pleiotropic cytokine, it plays an essential role not only in the innate immunity but also for linking of innate to adaptive immune response. Although, some immune cells such as monocytes and macrophages secrets IL-6, it is also produced by non-immune cells (e.g. fibroblasts, endothelial and mesenchymal cells) as well ${ }^{79}$.

\section{IL-6 signaling}

The biological effects of the circulating IL-6 are mediated through activation of IL-6 receptor (IL-6R) complex and its downstream intracellular signaling. IL-6R complex consists of two compartments: the IL-6 binding chain and the signal-transducing structure. While the glycoprotein 130 (gp130) as signal-transducing chain is shared in all IL-6 superfamily 
members, the receptor binding structure has instead unique feature in each of the family members ${ }^{80}$.

The secreted IL-6 binds to either the transmembrane or the soluble form of IL-6R, thus triggering either classical signaling in case of biding to the transmembrane receptor or transsignaling in case of binding to the soluble form. The membrane-bound form is expressed on hepatocytes, megakaryocytes, some leukocytes, brain parenchyma, microvasculature and peripheral nerves, whereas the soluble form resulted from splicing or proteolysis of the transmembrane receptor mRNA is present in human serum ${ }^{81}$. However, both trans-signaling and classical receptor signaling pathways, require activation of the signal- transducing chain, gp130.

The abundancy of circulating soluble IL-6R and the wide expression of heterodimeric subunits of gp130 on immune and non-immune cells allows IL-6 to exert its diverse effects on a broader set of cell types than of those only expressing IL-6R. In fact, the pleiotropic effect of IL-6 is due to the wide expression of gp $130^{82}$.

Interaction of the IL-6/IL-6R complex with gp130 triggers the activation of two downstream signaling pathways. The cytoplasmic domain of gp130 contains two motifs, called Box1 and Box2, which activate Janus tyrosine kinases (JAK) family; JAK1, JAK2, JAK3 and Tyk-2. Phosphorylation of other tyrosine residues of the cytoplasmic domain of gp130, simultaneously, leads to the recruitment of the signal transducer and activator of transcription (STAT) and Src homology protein 2 tyrosine phosphatase-2 (SHP2) $)^{79}$.

The former pathway is called JAK-STAT3 by which some tyrosine residues in the proximal site of cytoplasmic domain of gp130 triggers the activation of STAT1 and STAT3 ${ }^{83}$. Tyrosine residues located in the midportion of the cytoplasmic domain, activates MAPK pathways by phosphorylation of SHP2. Given that the gp130 is the common signal transducing domain in several cell types, the distinct biological activities of IL-6 in each cell type depends on which regions of cytoplasmic domain of gp130 is activated ${ }^{84}$.

The expression of IL-6 is however regulated by two proteins known as suppressor of cytokine signaling 1 (SOCS1) and SOCS3 which are induced by the transcription factor STAT3. In a negative feedback loop, SOCS1 and SOCS3 bind to respectively JAK and gp130 cytoplasmic domain to inhibit IL-6 intracellular signaling ${ }^{85,86}$. 


\section{Biological role of IL-6}

IL-6 was initially known by different names which were based of its biological activities. For its ability to differentiate lymphocytes B and produce antibody was named B-cell stimulatory factor $2(\mathrm{BSF}-2)^{87,88}$, whereas for its antiviral activity, similar to IFNs, was termed IFN $-\beta_{2}{ }^{89}$. It was also labeled as hepatocyte-stimulating factor (HSF) due to its role in inducing acute phase proteins by hepatocytes. The production of CRP, serum amyloid A, fibrinogen and haptoglobin in response to IL-6 is rapidly increased ${ }^{90,91}$, while the production of some other proteins such as albumin, transferrin and fibronectin are decreased ${ }^{92,93}$.

Circulating IL-6 released in the early phase of inflammation regulates the serum level of iron by induction of hepcidin. Hepcidin blocks the iron transporter protein, leading to hypoferremia and subsequently anemia ${ }^{94}$. IL-6 simultaneously enhances the maturation of megakaryocytes and in turn the production of thrombocytes ${ }^{95}$. It also promotes the activation and proliferation of T lymphocytes which helps to respond to intracellular (by T helper 1) and extracellular (by $\mathrm{T}$ helper 2) pathogens but inhibits proliferation of regulatory $\mathrm{T}$ lymphocytes, resulting in dysregulation and prolonged course of inflammatory responses ${ }^{96,97}$.

Although the pyrogenic potency of IL-6 injected peripherally has been shown to be weak and mainly dependent on the other potent pyrogen such as IL- $1 \beta^{98}$, several studies on experimental animals indicate the critical role of IL-6 in fever ${ }^{99,} 100,101,102$.

\section{Prostaglandins}

PGs are important lipid-based mediators that act as signal transducer substance. They are abundantly released at the site of inflammation and injury. These potent mediators are produced by many cells upon an immune challenge. Apart from the proinflammatory properties of PGs which accounts for their role in the initiation of inflammatory response, due to their high biological potency, they also play essential role in the development of inflammatory responses by increasing the vascular permeability and therefore contributing in the generation of cardinal signs of inflammation ${ }^{103}$.

PGs belong to a big family of prostanoids which consist of four bioactive forms e.g. $\mathrm{PGE}_{2}$, $\mathrm{PGI}_{2}$ (also known as prostacyclin), $\mathrm{PGD}_{2}$ and $\mathrm{PGF}_{2 \mathrm{a}}$ as well as one thromboxane (TX) called $\mathrm{TXA}_{2}$ 


\section{Biosynthesis of PGs}

Arachidonic acid as prostanoid precursor is hydrolyzed by phospholipase $\mathrm{A}_{2}$ from cell membrane phospholipids ${ }^{104}$. AA is subsequently converted to an unstable intermediate metabolite called $\mathrm{PGH}_{2}$. This sequential enzymatic process is governed by $\mathrm{COX}$ enzymes which are also known as prostaglandin-endoperoxide synthase (PTGS $)^{105}$.

Two isoforms of COX enzymes with distinct expressional pattern are identified: COX-1 with constitutive expression in nearly all organs and COX-2 as an inducible enzyme, mostly expressed under inflammatory conditions in the liver, lung, and brain ${ }^{106}$.

The conversion of the intermediate metabolite, $\mathrm{PGH}_{2}$, to a series of prostanoids is mediated by tissue-specific isomerase and synthase enzymes. For example, $\mathrm{PGE}_{2}$ is metabolized by two isozymes of PGE synthase (PGES) enzymes, the cytosolic and microsomal isoforms ${ }^{107,} 108$. Induction of cytosolic PGES (cPGES) is more coupled with expression of COX-1 in the basal condition, while the microsomal PGES (mPGES) expression is induced together with COX-2 enzyme upon an immune challenge ${ }^{109,110}$. This implies a role of microsomal isozyme in the inflammatory responses.

Although prostanoids are produced by nearly all cells in the body, each cell has its own specific prostanoid profile in which one or two PG or TX are produced predominantly. For example, macrophages mainly produce $\mathrm{PGE}_{2}$ and $\mathrm{TXA}_{2}$ while mast cells are more in favor of $\mathrm{PGD}_{2}$ production (Fig. 2) ${ }^{111,112}$.

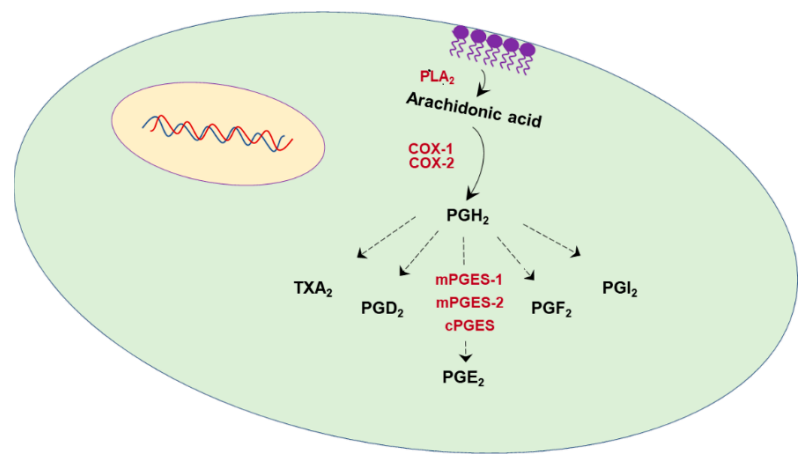

Figure 2. Biosynthesis of prostaglandins. 
Apart from that, the prostanoid profile in each cell is widely influenced by the cellular activation as well, meaning the level of each prostanoid in the respected cells is different in the resting mode compared to under immune-challenged conditions ${ }^{112}$.

\section{PGs in inflammation}

Among all prostanoids, $\mathrm{PGE}_{2}$ is of the particular interest due to its dual function. As its physiological role, it contributes to the regulation of immune responses, blood pressure and gastrointestinal integrity. In pathological conditions, the expression of inflammatory PGE2 synthesizing enzymes, COX-2, and mPGES-1, are upregulated by proinflammatory cytokines, resulting in the induction of inflammatory $\mathrm{PGE}_{2}{ }^{113}$.

The secreted $\mathrm{PGE}_{2}$ exerts its biological effects by activating 4 subtypes of E prostanoid (EP) receptors. $\mathrm{PGE}_{2}$ has been shown to have higher affinity for the EP3 and EP4 subtypes, but lesser to EP1 and EP2 ${ }^{114,115}$. Activation of EP1 receptors on peripheral sensory neurons by $\mathrm{PGE}_{2}$ triggers inflammatory pain responses, which is a classic sign of inflammation ${ }^{116}$. Simultaneously by increases the microvascular permeability and arterial dilation, it contributes to another cardinal signs of inflammation, edema in the inflamed tissue ${ }^{117}$.

$\mathrm{PGI}_{2}$ is also a potent vasodilator and a key PG in the regulation of the cardiovascular system. Endothelial cells and vascular smooth muscle cells are the main source of $\mathrm{PGI}_{2}$. It plays a role in inhibition of platelet aggregation and leukocyte adhesion to the endothelium ${ }^{118}$. It also contributes to edema and pain in the early phase of acute inflammation ${ }^{119}$. In fact, bradykinin enhances the formation of $\mathrm{PGI}_{2}$ and subsequently increase the permeability of vascular endothelium which leads to edema in the affected tissue. The presence of PGI2 receptors in the DRG neurons and the spinal cord which are the main sensory part of nociceptive pathway indicates a role of $\mathrm{PGI}_{2}$ in nociceptive pain during acute inflammation ${ }^{120}$.

$\mathrm{PGD}_{2}$ is produced in the nervous system and the periphery. Within the nervous system it has been shown to be linked to the pain perception and other brain activities such as sleep ${ }^{121,122}$. It is also synthesized by mast cells and some leukocytes that are specialized for acute allergic responses $^{123}$. 
$\mathrm{PGF}_{2 \mathrm{a}}$, either synthesized directly from $\mathrm{PGH}_{2}$ or metabolized by $\mathrm{PGD}_{2}$ and $\mathrm{E}_{2}$, is abundantly present in the plasma and urine under physiological condition, however it has recently been shown to also play important role in acute inflammation ${ }^{124}$.

$\mathrm{TXA}_{2}$ has a very short half-life and degraded to biologically inactive form termed $\mathrm{TXB}_{2}$. As a potential proinflammatory mediator, it contributes in several physiological and pathological conditions such as platelets adhesion and aggregation and activation of endothelial cells in the inflammatory responses ${ }^{125}$.

\section{Endothelial cells in inflammation}

Although blood monocytes and tissue macrophages play crucial role in the initiation of an inflammatory response, the role of endothelial cells in the progression of the acute inflammatory response and the clinical manifestation of a local inflammation should not be understated.

The initial phase of the acute phase response is mediated by the "alarm cytokines", released from activated monocytes and macrophages in response to an infectious stimulus. This includes the proinflammatory cytokines with pleiotropic effect to act both locally and distally e.g. IL-1, IL-6 and TNF- $\alpha^{47}$. As a result, proinflammatory cytokines (e.g. IL-1 and TNF- $\alpha$ ) activate surrounding cells in the stromal tissue such as fibroblasts and endothelial cells. The secondary wave of cytokines and other inflammatory mediators such as $\mathrm{PGE}_{2}$ is produced by fibroblasts and endothelial cells which enhance the progression of more complex aspects of the acute phase response ${ }^{126}$.

Other local immune cells such as mast cells, a type of tissue-resident immune cells, also release histamine and chemotactic factors (e.g. IL-8 for neutrophils and MCP-1 for mononuclear cells) by which more monocytes, macrophages and other leukocytes such as neutrophils are recruited to the site of inflammation ${ }^{127}$. In fact, circulating leukocytes require endothelial cells for the migration from circulation to the local site of inflammation.

Endothelial cells form a tight sealing line of blood vessels and play crucial role as an interface between circulating blood and tissues. From a homeostatic point of view, keeping the balance for the fluid passage, restriction of the transcellular flux and regulating the vascular tone are the main challenging tasks of endothelial cells ${ }^{128}$. Upon activation of the endothelial cells by 
the first wave of cytokines, the expression of intracellular adhesion molecules (ICAM) and integrins in these cells facilitate the migration of recruited leukocytes through sequential steps $^{129}$

On the other hand, the infiltrated leukocytes and residential tissue immune cells secret their own set of proinflammatory cytokines and inflammatory mediators including histamine, bradykinin, thrombin, platelet-activating factor (PAF), reactive oxygen species (ROS), nitric oxide (NO) and products of the arachidonic cascade (PGs and TX $)^{51,130}$. These factors mediate the classical signs of a localized acute inflammation: heat, redness, swelling and pain.

For instance, ROS, NO and some of the arachidonic acid cascade products (e.g. PGs) regulate the vascular tone, resulting in the vasodilation and vascular permeability ${ }^{131}$. Dilation and leakage of blood vessels facilitate the passage of other blood cells into the inflamed/damaged tissue and cause tissue edema (i.e. swelling), redness and heat. On the other hand, PAF activates platelet and promotes coagulation which leads to the occlusion of small blood vessels to prevent the spread of infection ${ }^{132}$. Bradykinin released during the clotting cascade and histamine, one of the first secreted mediators in the site of inflammation, cause pain and edema ${ }^{130}$.

As described, endothelial cells play a crucial role in the progression of the acute phase response which is not only limited to their role in communication between the blood circulation and the inflamed tissue but also for their role in the clinical manifestations of the inflammatory response as well as involving the systemic phase of inflammation. 


\section{Sickness behavior}

Activation of immune cells initiates an array of immune reactions (i.e. acute phase response), resulting in a localized acute inflammation with four cardinal signs, as mentioned earlier. However, the effect of proinflammatory cytokines is not limited the site of inflammation. Once the local endothelium of the surrounding tissue is activated and the second wave of cytokines are released, the acute phase response progresses to the systemic inflammatory response. These proinflammatory cytokines coordinate the local and systemic inflammatory responses, trigger endocrine, autonomic and behavioral changes in sick individuals, known as sickness behavior $^{133,134}$.

Sickness behavior is a brain-mediated adaptive response to protect and ensure the survival of sick individuals. The clinical manifestations of sickness behavior are very broad and consist of fever (elevation of body temperature above its homeostatic set-point), anorexia (loss of appetite), fatigue (extreme tiredness), malaise (general discomfort), hyperalgesia (increased pain sensitivity), anhedonia (loss of pleasure), lethargy (lack of energy), depressed mood, increased anxiety and reduced activity ${ }^{135}$.

These physiological and metabolic changes benefit the host to fight infections through complex but coordinated mechanisms. The brain mediates set of metabolic responses such as lethargy and fatigue to conserve energy needed for the function of vital organs. At the same time, the elevation of body temperature in response to an infectious agent is a physiological adaptive response that prohibits the growth of infectious agent and enhance immune cells activities to fight infection ${ }^{136}$. 


\section{Fever}

Fever or "pyrexia" is one of the generalized signs of the systemic inflammatory response that is characterized by the elevation of the body temperature above its homeostatic balance-point in the hypothalamic thermoregulatory center ${ }^{137}$.

The temperature of internal organs varies to a very small degree based on their location. The temperature of thoracic, abdominal viscera and brain, referred to as "the core body temperature", is in the range of $36.5-37.5^{\circ} \mathrm{C}$, whereas this range for the oral temperature changes from $36.4^{\circ} \mathrm{C}$ to $37.2^{\circ} \mathrm{C}$ in healthy individuals $18-40$ years of age. The rectal temperature is however slightly higher than oral temperature in the range of $36.8-37.6^{\circ} \mathrm{C}$ probably due to the exhalation of heat through the oral cavity ${ }^{138}$.

The body temperature not only varies based on the sex, age and activity, it also undergoes a daily variation, known as circadian rhythm, from the lowest in the morning (6 A.M.) to the highest in the afternoon (4-6 P.M.). The mean daily temperature is about $0.5^{\circ} \mathrm{C}$, meaning the maximal oral temperature in the morning and afternoon are $37.2^{\circ} \mathrm{C}$ and $37.7^{\circ} \mathrm{C}$, respectively ${ }^{138}$. Thus, fever is defined as an oral temperature higher than $37.2^{\circ} \mathrm{C}$ in the morning or $37.7^{\circ} \mathrm{C}$ in the afternoon.

The body temperature is sometimes elevated or lowered; "hyperthermia" or "hypothermia", respectively. Hyperthermia or heat stroke is characterized by excessive endogenous heat production or exogenous heat exposure which exceeds heat dissipation (vasodilation and sweating $)^{139}$. Hyperthermia, in contrast to pathogenic fever, has rapid onset and is not controlled by antipyretic medications ${ }^{140}$. Hypothermia is identified by exposure to extremely low ambient temperature in which heat gain (vasoconstriction and shivering) is not adequate to compensate the heat loss ${ }^{10,141}$.

Under these circumstances, the setting of the hypothalamic set point is unaffected while the hypothalamic regulatory responses fail to maintain the homeostatic temperature ${ }^{139,141}$. In fever, however, the hypothalamic set point is altered, meaning that the threshold of body temperature for heat and cold defenses are displaced ${ }^{7}$. Three distinct phases have been described in experimental model of inflammation-induced fever ${ }^{142,143,144}$.

In the initial phase of immune-induced fever, the hypothalamic set point for both thermoeffectors (heat and cold) is elevated by pyrogens, resulting in a "hypothermic phase" where the body temperature is below the hypothalamic set point ${ }^{145,146}$. The magnitude and 
latency of the hypothermic phase seem to be directly proportional to the pyrogen dose and the ambient temperature ${ }^{144}$. Albeit it is negatively influenced by the level of stress in the experimental animal models. Stressed-induced hyperthermia as a result of handling and needle prick in animals masks the magnitude of hypothermic phase, unless a lower dose of pyrogens or different injection routes are applied ${ }^{142}$.

The second phase of the febrile response is mediated by the anterior hypothalamic thermosensitive neurons, by sensing the temperature fall and therefore activating the cold defense mechanisms (vasoconstriction and thermogenesis) to increase the body temperature that matches the new set point ${ }^{43}, 145$. This phase is accompanied by behavioral changes e.g. chills due to the peripheral vasoconstriction and warmth-seeking behavior ${ }^{12}$.

As fever develops, a parallel shift of thermoeffector thresholds occurs, meaning that the hypothalamic set point for heat defense (vasodilation) remains high while the threshold for cold defense (thermogenesis) decreases ${ }^{143}$. As a result of this immense interthreshold zone, the thermoeffective responses are no longer operated and the body temperature begins to follow the ambient temperature (i.e. passive heat exchange), similar to poikilothermic animals ${ }^{10}$. In defervescence or subsidence phase, the hypothalamic set point is reset downwards, and the body temperature returns to its basal level via activation of heat defense mechanisms ${ }^{43}$.

All phases of fever, similar to cold-defense response, are accompanied by warm-seeking behavior $^{146}$. However, the hypothermia induced by the higher doses of pyrogen is shown to be accompanied by the cold-seeking behavior in experimental models ${ }^{147,148}$.

Notably, the duration of fever seems directly proportional to the concentration and continued production of pyrogenic substances ${ }^{149}$. 


\section{Pathogenesis of fever}

Fever is the hallmark of infectious disease and induced by fever-inducing molecules, called pyrogens ${ }^{54}$. Bacterial products such as LPS and foreign antigens, known as exogenous pyrogens, bind to PRRs expressed by leukocytes (i.e. TLR-4 in case of LPS as ligand), resulting in the activation of NF- $\kappa \mathrm{B}$ and production of proinflammatory cytokines (e.g. TNF- $\alpha$, IL-1 and IL-6) which are known as endogenous pyrogens ${ }^{51}$. Activation of NF- $\kappa \mathrm{B}$, the common pathway in the signaling cascade of pyrogenic cytokines, leading to the expression of COX-2 enzyme and ultimately synthesis of $\mathrm{PGE}_{2}{ }^{149}$.

Fever is known to be dependent on COX-2 and the downstream enzyme mPGES-1 ${ }^{150,151}$. Upon immune challenge, COX-2 is induced in many organs including lung, liver, and brain ${ }^{106}$. Within the brain, COX-2 is however primarily induced in perivascular and endothelial cells along small vessels ${ }^{152,153,154,155}$. Although, the expression of COX-2 in response to a systemic inflammation is observed more or less throughout the small venules of the entire brain, the POA of the hypothalamus seems to have the highest level of expression likely due to its high density of small venules ${ }^{156,157}$.

Although $\mathrm{PGE}_{2}$ is an essential mediator in the pathogenesis of fever ${ }^{158}$, the cellular source of its synthesizing enzymes, COX-2 and mPGES-1, responsible for the febrile response had not been determined ${ }^{159}$. Thus, our first research question was to address the cellular source of pyrogenic $\mathrm{PGE}_{2}$ (See paper I).

The mechanism by which the pyrogenic $\mathrm{PGE}_{2}$ induces fever is similar to the cold-defense response. $\mathrm{PGE}_{2}$ exerts its pyretic effect via binding to $\mathrm{EP} 3$ receptors on warm-sensitive neurons in the MnPO, the thermoregulatory center in the brain ${ }^{160,161}$. Stimulation of EP3-expressing neurons by pyrogenic $\mathrm{PGE}_{2}$, reduces the GABAergic projection of these neurons to $\mathrm{DMH}$ and rRPA, resulting in the activation of $\mathrm{CVC}, \mathrm{BAT}$ and shivering thermogenesis in the skeletal muscles $^{13}$.

In other words, when the firing rate of preoptic EP3-expressing neurons is decreased by $\mathrm{PGE}_{2}$, the heat loss responses are suppressed, and the hypothalamic set point is then elevated. Inhibition of the warm-sensitive neurons firing rate, in contrast, increases the firing rate of cold-sensitive neurons and therefore provokes the cold-defense responses (Fig. 3) ${ }^{162}$.

Once the level of pyrogens declines, the firing rate of cold-sensitive neurons diminishes, leading to the inhibition of the heat production. Subsequently, the firing rate of warm-sensitive 
neurons in POA returns to its normal level which is the higher rate in order to activate the heat $\operatorname{loss}^{162}$.
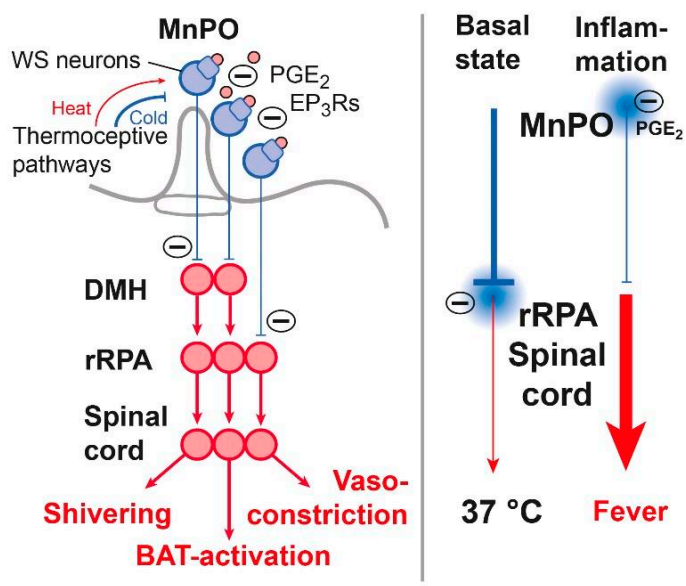

Figure 3. The mechanism of fever induction by pyrogenic $\mathrm{PGE}_{2}$. Modified from Blomqvist and Engblom, $2018^{163}$.

Although, $\mathrm{PGE}_{2}$ is the critical mediator in the pathogenesis of fever ${ }^{158}$, different phases of an inflammatory fever are believed to be mediated by $\mathrm{PGE}_{2}$ from different sources.

The initial phase of fever was earlier believed to be mediated by $\mathrm{PGE}_{2}$ produced by pulmonary and hepatic macrophages ${ }^{164}$, whereas the later phase is believed to be mediated by the locally produced $\mathrm{PGE}_{2}$ in the brain ${ }^{152,153,154,155}$. As the initial phase of fever in animals that intravenously injected with neutralizing antibody against $\mathrm{PGE}_{2}$ was not fully blunted and the fact that the antibody is unable to cross the blood-brain barrier (BBB), the residual fever is assumed to be mediated by $\mathrm{PGE}_{2}$ from other sources. This hypothesis was later examined by Engström and collaborates in an elegant study by which the initial phase of fever was shown to be dependent on the locally produced $\mathrm{PGE}_{2}$ in the brain, but not dependent on the peripherally produced $\mathrm{PGE}_{2}{ }^{165}$.

However, how peripherally circulating mediators can signal to brain despite its non-fenestrated vessels remains unclear. 


\section{Blood-brain barrier}

The brain is well-protected by two distinct barriers: the blood-CSF and BBB. The barriers highly regulate the influx and efflux of ions and biomolecules in and out the brain ${ }^{166}$. This optimal maintenance of the neural network results from a complex multicellular structure. At the $\mathrm{BBB}$, this robust structure is composed of mainly microvascular endothelial cells, pericytes, astrocytes and the non-cellular basement membrane ${ }^{167}$.

Brain endothelial cells are the core element of BBB and have unique properties compared with peripheral endothelial cells. The presence of interendothelial junctions, known as adherence and tight junctions as well as the absence of fenestrae are all unique features of the brain endothelium which acts as a brick wall and restricts the cellular passage at the $\mathrm{BBB}^{168}$. Due to the low transcytotic activity of the brain endothelial cells that greatly limits the transcellular flux ${ }^{169}$, another specific feature of brain endothelium comes into play. The biomolecules and ions traffic are instead managed by a set of specific metabolic enzymes and transporters across the $\mathrm{BBB}$ endothelium in a polarized manner ${ }^{170}$.

The neurovascular unit (NVU) consists of two other cell types: pericytes and astrocytes ${ }^{167}$. These are the main cell types surrounding the brain endothelium and therefore their close interactions with NUV is essential for induction, maintenance and eventually development of the $\mathrm{BBB}^{171}$.

Pericytes cover the outer wall of all endothelial cells. Brain vasculature has the highest coverage of pericytes compared to the peripheral vasculature ${ }^{172}$. High abundance of alphasmooth-muscle actin in NVU pericytes unable them to regulate diameter of the capillary vessels as well as cerebral blood flow ${ }^{173}$. The essential role of pericytes in the BBB formation is mainly due to the close anatomical association of pericytes with the brain endothelial cells through $\mathrm{N}$ cadherin junctions ${ }^{174}$. In addition to their role in BBB formation, pericytes have been shown to regulate the integrity of BBB by polarization of astrocyte end-feet ${ }^{175}$.

Astrocytes end-feet are in proximity to either blood vessels or neural processes and thus act as a linkage to synchronize the level of metabolites in the cerebral vasculature and regulate vasodilation via transmitting signal from neuronal activity ${ }^{176}$. However, as the most abundant cell type in the brain, they not only provide nutrition for neurons but also play supportive role for the cerebral vasculature under inflammatory conditions ${ }^{177}$. Moreover, astrocytes control 
homeostatic balance of the neuronal microenvironment by regulating the exchange of ions and transmitters ${ }^{178}$.

Since there are no direct cellular contacts between astrocytes and the brain vasculature, the crosstalk between astrocytes and the brain endothelium is mediated through soluble factors secreted by pericytes, endothelial cells and astrocytes ${ }^{179}$. The extracellular matrix (ECM) forms an acellular member of NVU, known as basement membrane (BM) which structurally supports BBB integrity by serving as ligands for transmembrane receptors expressed by members of the $\mathrm{NVU}^{180}$. BM controls the direction of molecules and metabolites exchange by redistribution of transporters across the cerebral vasculature ${ }^{171}$.

BM comprises of two compartments, an inner vascular membrane surrounding the abluminal side of endothelial cells and an outer vascular membrane covering pericytes. The space between these two compartments is known as perivascular space which is infiltrated mainly by perivascular macrophages (PVMs) ${ }^{179}$.

Under physiological conditions, PVMs contribute to the brain integrity by restricting the passage of macromolecules into the brain parenchyma in highly permeable areas of the BBB lacking tight junctions ${ }^{181}$. As brain resident immune cells, the phagocytic ability and expression of major histocompatibility complex (MHC) class II molecules enable them to serve as immune surveillance arm, by facilitating the lymphatic clearance and maintenance of the brain homeostasis ${ }^{182}$. However, under sever inflammatory conditions such as viral infections in the brain, PVMs have been found to indirectly influence the leukocyte trafficking through the $\mathrm{BBB}$, resulting in the disruption of $\mathrm{BBB}^{183}$. In contrast, they may also provide a protective role to prevent BBB disruption, depending on the nature of inflammatory stimulus ${ }^{184,185}$.

Another unique feature of the brain is the presence of circumventricular organs (CVOs), regions of the brain that contain highly permeable capillaries lacking tight junctions ${ }^{186}$. Unlike non-fenestrated brain endothelium, CVOs capillaries are fenestrated and enable rapid neurohumoral exchanges and communication between circulation and neurons ${ }^{187}$. Organum vasculosum of the lamina terminalis (OVLT) is one of the CVOs regions that exist in the vicinity of thermoregulatory neurons in the preoptic hypothalamus. 


\section{Immune-to-brain signaling in fever response}

Although the $\mathrm{PGE}_{2}$ produced in the brain is shown to mediate the initial phase of fever ${ }^{165}$, it remains unclear how the peripherally pyrogenic cytokines or inflammatory mediators such as $\mathrm{PGE}_{2}$ can signal the brain and initiates the febrile response. Several hypotheses have been postulated to mediate this signaling.

One of the early hypotheses was mainly based on the discovery of the endogenous pyrogens ${ }^{54}$ ${ }^{188}$, which was later termed as pyrogenic cytokines ${ }^{55}$. In this model, endogenous cytokines (i.e. IL-1 $\beta$, IL-6 and TNF- $\alpha$ ) that are produced upon exposure of peripheral immune cells to exogenous pyrogens ${ }^{189}$, are release in the bloodstream and reach the thermoregulatory center. According to this model, pyrogenic cytokines can pass BBB via transporters or through the OVLT $^{190,191,192}$. However, later studies have shown that their passage to the brain is shown to be very slow due to their bulky nature and that the quantity of these cytokines in the brain required for fever induction is insufficient ${ }^{193,194}$.

The vicinity of OVLT structure to the POA and expression of pyrogenic cytokines receptors by these cells ${ }^{195,196,197,198}$, increased the interest to investigate its potential role in immune-tobrain signaling, particularly in the induction of fever. These non-fenestrated capillaries structure have been shown to respond to even a lower dose of endogenous immune stimuli and produce cytokines in response to peripheral immune challenges ${ }^{199}$.

In support of a role of the OVLT, lesions in the anteroventral third ventricle which includes the OVLT structure resulted in the attenuated fever response in guinea pigs peripherally challenged with LPS ${ }^{200}$. As other studies with lesions in the OVLT reported intact fever response and even elevated fever ${ }^{201}$, the role of OVLT in relaying the inflammatory signals from the periphery to the POA of the hypothalamus became contradictory.

Fever is blunted in animals with ablated OVLT that peripherally injected pyrogens, but not in case of pyrogens injected intracerebroventricularly, indicating that the circulating pyrogens may act on brain endothelium side of OVLT by binding to their respective receptor ${ }^{198}$.

Given that the cytokine receptors in the brain can also be activated by the locally produced cytokines $^{202}$, even in the absence of OVLT structure, the pyrogenic cytokine receptors became another focus of interest in immune-to-brain signaling in the febrile response. Intracerebrally or intravenously injection of exogenous IL-1 $\beta$ in animals with manipulated IL-1R1 in the brain endothelium resulted in a blunted fever response, indicating the critical role of the brain 
endothelium IL-1R1 in the IL-1 $\beta$-induced fever ${ }^{203}$. However, the brain endothelium IL-1R1 is not indispensable for the fever response when the immune challenging factor is LPS ${ }^{204}$. This phenomenon can be explained by the fact that LPS not only triggers the activation of IL-1 $\beta$, also induces other pyrogenic cytokines such as IL-6. Despite the low pyrogenic property of IL$6^{100}$, the febrile response is shown to be abolished in absence of IL-6. Animals given neutralizing antibody against IL-6 or with the global deletion of IL-6 were unable to mount fever upon LPS challenge $99,102,205$. However, the mechanism by which circulating IL-6 contributes in immune-to-brain signaling in the febrile response has remained to be investigated. Hence, we addressed the specific cell type and mechanism by which the pyrogenic IL-6 induces the expression of $\mathrm{PGE}_{2}$ and mounts LPS-induced fever (paper II).

Another proposed pathway for immune to brain signaling is transmission of the inflammatory signals to the brain through the vagus nerves. The vagus nerves are the longest peripheral motor and sensory fibers of the autonomic nervous system. They originate from the brain stem and bilaterally innervates the thorax and abdomen. The two main branches, subdiaphragmatic and abdominal, control parasympathetic function of the heart, lungs, and gastrointestinal tract ${ }^{6}$.

Fever was shown to be abolished in vagotomized guinea pigs injected intravenously with LPS and the level of preoptic $\mathrm{PGE}_{2}$ was not elevated ${ }^{206}$, whereas, vagotomized rats challenged intravenously with LPS showed increased level of $\mathrm{PGE}_{2}$ in the $\mathrm{CSF}^{207}$. However, the early phase of fever in vagotomized rats that were challenged intravenously with LPS was reported to be abolished in other studies, suggesting a role of the vagus nerve in the early phase of polyphasic fever ${ }^{208,209}$. This idea was later challenged as vagotomy did not abolish the fever induced by intravenous injection of $\mathrm{PGE}_{2}{ }^{210}$.

Electrical stimulation of the vagus nerve in the LPS-challenged rats showed that the production of TNF- $\alpha$ from liver was reduced ${ }^{211}$, indicating protective aspects of the vagus nerves against LPS-induced inflammation which contrast with the role of vagus nerves in the induction of fever in the LPS-challenged guinea pigs ${ }^{206}$.

While the role of vagus nerve in transmission of signals from the peripheral tissues to the CNS for fever induction has been controversial, it has been speculated that the localized peripheral inflammation mediates fever by signaling through the somatic afferent fibers ${ }^{212,213}$. LPS together with anesthetic were applied in air pouch or artificial subcutaneous chamber which are models of localized peripheral inflammation ${ }^{214}$. Although the fever response was abolished in this model, the blood levels of IL-6 were intact, probably due to the leakage from the local 
inflammatory site. However, the anesthesia did not only influence the activation of the immune response $\mathrm{e}^{215,216}$, but also to a large degree the temperature response (Fig.4) ${ }^{10}$.

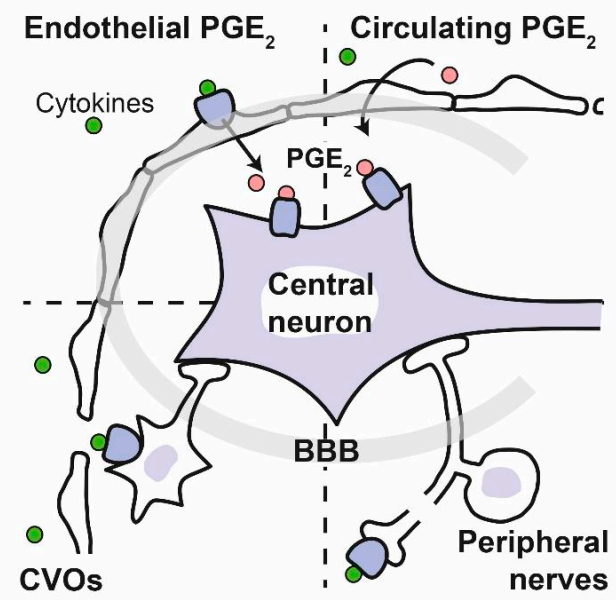

Figure 4. Suggested pathways for immune-to-brain signaling in fever. Modified from Blomqvist and Engblom, 2018 ${ }^{163}$.

The discovery of $\mathrm{PGE}_{2}$ production in the brain microvasculature indicated that these cells are critical transducers of immune-to-brain signaling in the febrile response $\mathrm{e}^{217,218}$. Although, the brain endothelium was first identified as cellular source for $\mathrm{PGE}_{2}$ and COX-2 ${ }^{152,153}$, a few other studies indicated another cellular source, the perivascular cells ${ }^{154}, 155,219$. It has also been proposed that the cellular source of $\mathrm{PGE}_{2}$ may depend on the type and dose of pyrogens, meaning that while higher doses of LPS induce the expression of $\mathrm{PGE}_{2}$ in the brain endothelium, lower doses of LPS or IL- $1 \beta$ induce its expression in the perivascular cells ${ }^{155,220}$ . Despite the discovery of the brain endothelium as the main cellular source of mPGES-1 159 , ${ }^{221}$, expression of mPGES-1 was reported to be induced in the perivascular cells as well ${ }^{220}$. Thus, the controversy of which cell type is the cellular source of $\mathrm{PGE}_{2}$ is remained to be addressed by cell type-specific modulation of expression of $\mathrm{PGE}_{2}$ synthesizing enzymes. By using such a model, we investigated the role of brain vasculature $\mathrm{PGE}_{2}$ in inflammationinduced fever models to address the cellular source of pyrogenic $\mathrm{PGE}_{2}$ (paper I). 


\section{Paracetamol}

Aside from the beneficial aspects of fever to restrict the growth of pathogens ${ }^{222}$ and enhance the activity of immune cells $\mathrm{s}^{223}$, high fever $\left(40.5^{\circ} \mathrm{C}\right)$ or even prolonged moderate fever can be detrimental ${ }^{224}$. In most patient categories, high fever results in a severe dehydration, negative nutrient balance, cardiopulmonary strain and eventually organs failure ${ }^{225}$, a condition that requires medical interventions and treatment with antipyretic drugs ${ }^{226}$.

\section{The antipyretic effect}

Paracetamol, also known as acetaminophen, is one of the most commonly used antipyretic drugs. Despite being a potent antipyretic and analgesic drug, its mechanism of action is not fully understood. The antipyretic effect of paracetamol, similar to non-steroidal antiinflammatory drugs (NSAIDs), is assumed to be exerted by inhibition of PGs production (i.e. PGE2, PGI2, PGF2 $\alpha$ and TXA2) ${ }^{227,228 .}$

The conversion of AA to $\mathrm{PGH}_{2}$ is catalyzed via two active sites of COXs isoenzymes ${ }^{229}$. The first step of AA conversion to $\mathrm{PGG}_{2}$ involves the cyclooxygenase site of COXs by which AA is oxidized and form hydroperoxide $\mathrm{PGG}_{2}$. The second step involves the peroxidase site of COXs where the conversion of $\mathrm{PGG}_{2}$ to $\mathrm{PGH}_{2}$ takes place ${ }^{106}$.

While, NSAIDs have been shown to compete with AA for the cyclooxygenase active site of COXs enzymes, paracetamol instead seems to act on peroxidase site of COXs by reducing the co-substrate (oxidase form) ${ }^{230}, 231$. This mode of action has been suggested to explain the efficiency of paracetamol in the brain which has lower peroxide concentration compared to the periphery ${ }^{232}$. On the other hand, lack of anti-inflammatory property in paracetamol may results from its low efficiency in a high peroxidase milieu such as inflammatory sites.

The antipyretic effect of paracetamol has been demonstrated to be exerted via inhibition of COX $-2^{233}$, which is a critical enzyme in the generation of fever ${ }^{234}$. Given that paracetamol can cross the BBB and its tissue-selectivity to centrally exert the antipyretic effect ${ }^{235,236}$, it is not unexpected that it may target the brain vascular endothelium COX-2 to inhibit the febrile response. Such a mode of action would be consistent with a study by Hinz and collaborators by which paracetamol inhibited over $80 \%$ of COX-2 in the vascular endothelium ${ }^{237}$. 


\section{The analgesic effect}

Similar to its antipyretic activity, the antinociceptive effect of paracetamol was also shown to be exerted centrally ${ }^{238}$. One of the postulated mechanisms of antinociceptive activity of paracetamol is inhibition of descending serotoninergic pathway ${ }^{239}, 240$, known as a main pathway in pain control, by involvement of the $5-\mathrm{HT}_{3}$ subtype of serotonin receptors ${ }^{241}$. On the other hand, another finding by detecting wide expression of EP3 receptors on the descending serotoninergic pathway reinforced the idea that the antinociceptive effect of paracetamol can be exerted by inhibition of $\mathrm{PGE}_{2}$ acting on the serotoninergic descending pain pathway ${ }^{242}$.

Paracetamol, either taken orally or injected intramuscularly or intravenously, is mainly metabolized in the liver via three metabolic pathways ${ }^{243}$. The majority of paracetamol is metabolized via glucuronidation and sulphation pathways to nontoxic and inactive forms, whereas a small percentage is oxidized by cytochrome P450 enzyme to form a toxic reactive form, called N-acetyl-p-benzo-quinone imine (NAPQI) ${ }^{244}$. NAPQI is detoxified by conjugation with glutathione groups ${ }^{245}$. In case of intoxication with paracetamol, excess NAPQI leads to the saturation of glutathione system and formation of ROS in mitochondria. Accumulation of ROS in the mitochondria results in hepatocellular toxicity and if left untreated subsequently causes liver failure ${ }^{243}$. N-acetylcysteine (NAC), instead, replenish glutathione stores and increase the activity of other pathways such as sulphation, thus it is considered as best treatment choice in the paracetamol overdose $\operatorname{cases}^{245}$.

Aside from liver, paracetamol is metabolized in other sites of the body such as CNS. In the brain and spinal cord, paracetamol is deacetylated to $\mathrm{p}$-aminophenol. $\mathrm{P}$-aminophenol is then conjugated with AA by the fatty acid amide hydrolase (FAAH) to form an active metabolite, the fatty acid amide $\mathrm{N}$-arachidonoylphenolamine (AM404) ${ }^{246}$.

Later on, studies on AM404 indicated an association of this active metabolite with the endocannabinoid system ${ }^{247}$. The endocannabinoid system consists of endogenous antinociceptive metabolites that act via cannabinoid (CB) receptors in the $\mathrm{CNS}^{248}$. AM404 is shown to indirectly act on the endocannabinoid system, in fact by activating TRPV1 receptors ${ }^{249}$. These receptors that are identified in nociceptive neurons of the trigeminal and $\mathrm{DRG}^{250}$, involve in the transmission and modulation of pain ${ }^{20}$. TRPV1, ligand of CB1 receptor, inhibits the uptake of endogenous cannabinoid, resulting in increased production of endogenous antinociceptive cannabinoid ${ }^{251}$. 
In addition to AM404, NAPQI has also been shown to be involved in the analgesic effect of paracetamol by activating TRPA1 receptor on the spinal nociceptive sensory neurons ${ }^{252}$. NAPQI, as TRPA1 agonist, is shown to reduce the neuronal excitability associated to neurotransmitter release and evokes TRPA1-mediated spinal antinociception.

Paracetamol is not only a potent antipyretic compound; it also induces profound hypothermia if given in high doses ${ }^{253}$. An experimental study in mice has revealed that the hypothermic response of paracetamol is TRPA1-dependant. Despite co-expression of TRPV1 with TRPA1 on a subpopulation of nociceptive sensory neurons, TRPV1 seems not to contribute to the hypothermic effect of paracetamol ${ }^{254}$. The role of TRPA1 channel in hypothermic and antinociceptive effects of paracetamol, raises the question whether the antipyretic activity of paracetamol is also TRPA1-dependant. In paper III, we examined the antipyretic effect of paracetamol in mice with global deletion of TRPA1 gene that were immune challenged with the pyretic dose of LPS. 


\section{Model of experimental fever}

Although, fever can be induced by several exogenous pyrogens in experimental animals, LPS from Escherichia coli, a Gram-negative bacterium, is the most commonly used exogenous pyrogen to induce a natural fever response ${ }^{144}$. The characteristic of an experimental fever depends on a variety of different factors which includes the dose of LPS, the route of injection, the ambient temperature, the period during the circadian cycle of the challenged host, the gender, the size, and the age of the animal.

Fever is shown to be induced by LPS in the range of 5-1000 $\mu \mathrm{g} / \mathrm{kg}$, albeit the intensity and duration of the febrile response is highly dose dependent ${ }^{144}$. On the other hand, LPS in high dose $(1000 \mu \mathrm{g} / \mathrm{kg})$ impairs the structure of the BBB. Except in studies with special focus on sepsis, the highest dose is not applicable when studying signaling pathways across the BBB.

In this thesis, we employed the established model of LPS-induced fever in which 100 (in paper III) or $120 \mu \mathrm{g} / \mathrm{kg}$ (in papers I and II) LPS were intraperitoneally administrated to mice in the beginning of the light cycle. Mice that were matched for the sex and age were kept in a room where the temperature was set to $29^{\circ} \mathrm{C}$. This temperature prevents cooling-evoked thermogenesis by the brown adipose tissue.

Intraperitoneal administration of LPS at these doses generates triphasic fever ${ }^{142}$. The first phase that initiates 1-1.5 h post-injection, is masked by a stress-induced hyperthermia caused by the handling. Following a transient hypothermia, the second and third phases continue with the rise in the core body temperature peaking at approximately $2-2.5 \mathrm{~h}$ and $5-6 \mathrm{~h}$ post-injection, subsequently.

\section{Transgenic mice}

Among experimental animals, mice are often used because of their well-characterized genome, short generation time and the low maintenance cost. Extensive studies of the mouse genome revealed high similarity of their genome to human which together with the development of transgenic technology facilitate studying the function of specific genes ${ }^{255,256}$. Global knockout 
lines are the most basic type of genetically modified model by which a specific gene is globally ablated in mice. To obtain such a mouse line, the DNA sequence of a gene of interest is altered and inserted into embryonic stem cells. The stem cells that contains mutant sequences of the gene of interest is then microinjected into a blastocyst and the embryo is then transferred to the uterus of wild type (WT) female mouse. Those offspring of this female mouse that are heterozygous for the knockout gene, are then interbred resulting in some of the offspring with homozygous knockout gene ${ }^{257,258}$. We used global knockout mouse line in the paper III where the TRPA1 gene was globally ablated in mice.

Although, the global knockout technology allows investigation of the gene of interest, the limitations of this technique must be taken into the consideration. For example, deletion of some genes can be lethal due to their vital role in the development, or a permanent gene deletion can trigger compensatory effect by other proteins that having redundancy for a specific cellular or molecular process.

Despite the popularity of the global knockout lines, lack of specificity to address the role of the target gene in a tissue-specific manner led to the development of other approaches such as conditional genetic manipulations in a selective cell type by Cre/lox system (Sternberg, 1981). In this model, the Cre recombinase from bacteriophage P1, recognizes lox P sequences inserted into in the genome. The function of Cre enzyme depends on the orientation of the lox P sites. If the lox $\mathrm{P}$ sites of the gene of interest shares same orientation, the Cre recombinase removes the genetic material between two lox $\mathrm{P}$ sites and if the lox $\mathrm{p}$ sites are inserted in different directions the genetic material between them are inverted.

To obtain a mouse line with selective conditional knockout in a specific cell type, two transgenic mouse lines should be generated, one with the Cre recombinase expressed under the promotor of a gene that only expressed in the cell type of interest and one with lox $\mathrm{P}$ sites around the gene of interest ${ }^{259}$. The offspring that is bred from these two lines, is a mouse line with selective deletion of the target gene in the cell type of interest.

This model can also be modified by ligand-sensitive technology by which the Cre recombinase is fused to a nuclear receptor, a modified human estrogen receptor (ER). Introducing tamoxifen (the ligand) activates translocation of the receptor to the nucleus where the Cre recombinase removes the target gene in the cell type of interest ${ }^{260}$. Such a technology provides high specificity and precision to control when the target gene in a specific cell type should be deleted. 
In the present thesis, we used this technology to generate conditional knockouts in selective cell types. In paper I, we generated mice with selective deletions of COX-2 and mPGES-1 in the brain endothelial cells. In paper II, we generated mice with deletion of IL-6R $\alpha$ in many cell types including brain endothelial cells, primary sensory ganglia, peripheral and the central nervous system.

\section{Temperature and activity recordings}

In this thesis, the telemetric recordings were employed to measure the core body temperature and the activity of freely moving animals. For temperature recordings, the telemetry system converts the emitted signals from a radio transmitter in the abdominal cavity of mice to a digital temperature signal via a software connected to the system. The radio transmitters were implanted in the abdominal cavity of the mice under general anesthesia with isoflurane. The postoperative pain was managed by the buprenorphine as painkiller. The operated mice were given at least one week of recovery and any mice showing signs of not being healthy were excluded from the experiment.

The locomotor activity of mice in paper I was also measured via telemetric recordings. The animal cage was hypothetically divided in midline; therefore, two zones were defined for the measurement of the locomotor activity. The activity of mice was estimated by determining the number of times they crossed the midline of the cage. As mice were implanted with transmitters, the location of transmitter reflected the location of the mouse.

Although, the telemetric recordings require a surgical procedure to implant the radio transmitters in animals, it provides greater accuracy and reliability in comparison with other methods such as rectal temperature recordings that require animal restraint in different time intervals.

\section{Immunohistochemistry}

Immunohistochemistry is a powerful technique for visualizing the location of the target protein with cellular resolution. The principle of the technique is detection of the target protein by a specific antibody which is called primary antibody. Depending on the expression level and 
accessibility of the target antigen, direct (only primary antibody) or indirect (primary and secondary antibodies) labeling can be used.

In paper I, we employed indirect labeling due to the higher sensitivity and its ability to amplify weak signals. In this method, the secondary antibody is conjugated with biotin which has high affinity to avidin. Then, the solution that contains avidin and peroxidase is added whereby the avidin-biotin-complex is formed. The complex can be then visualized by a chromogenic enzyme. In paper I, 3,3'-Diaminobenzidine (DAB) was used as chromogen and the intensity of staining was increased by employing a second chromogenic substance, nickel ammonium.

The target protein can also be detected and visualized by fluorescence dyes which are conjugated to the secondary antibody. Although the immunofluorescence staining has lower sensitivity in comparison with enzyme-based detection system, it is widely used for colocalization studies where more than one protein can be detected in a target tissue. In papers I and II, immunofluorescence staining was employed to co-localize the expression of COX-2 in the brain endothelial cells that are known to express lipocalin-2 or von Willebrand factor.

Despite the wide application of immunostaining to detect proteins, the specificity of the primary antibody can be an issue. Thus, including a negative control such as tissue or cells lacking expression of the target protein is always recommended. In addition, the immunostaining can be validated by including or excluding of the purified immunizing antigen with the pre-adsorbed primary antibody in which the staining should subsequently be absent or present in the end of the immunostaining procedure. However, these control methods have some limitations. For example, in case of using a monoclonal antibody, since the corresponding antigen is always absorbed by the antibody, having such a control would not reflect the specificity of the antibody. The specificity of an antibody can also be confirmed by using another technique such as western blot by which the antibody is specifically coupled to the corresponding tissue protein with expected molecular weight.

Another approach for verification of the staining specificity is to create a promoter-driven reporter line by using transgenic technology. We applied this method in paper II in which a mouse line was created with promoter-driven red fluorescent protein (tdTomato) in cells recombined by Slcolcl-CreER ${ }^{T 2}$. The method provided an advanced validation of the expressional pattern in the brain endothelial cells where the red tomato fluorescence is highly expressed. 


\section{Immunoassay}

The principle behind immunoassay is detection of the protein or lipid of interest by its specific antibody, similar to immunohistochemistry. However, immunoassay gives an objective quantification of the target analyte which is not yielded by immunohistochemistry. Moreover, due to the high sensitivity of immunoassay, very small amount of sample is required for quantification of the target analyte.

Different labeling systems exist to detect and quantify the concentration of the target analyte. In paper I, we employed the enzyme-linked immunosorbent assay (ELISA) for detection of IL-1 in the plasma. In brief, monoclonal antibody specific for IL-1 was pre-coated onto a microplate where the plasma of mice and standards for IL-1 were added. After incubation time, the microplate contents were washed for removal of unbound substance and the enzymeconjugated polyclonal antibody specific for IL-1 was added. The unbound enzyme-linked antibody was washed away and the corresponding substrate for the conjugated-enzyme was added, resulting in color development which is proportional to amount of IL-1. The color development was then stopped by a solution and the intensity of color was measured by EILSA reader.

Despite many advantages of ELISA, there are some limitations such as low throughput because not more than one analyte at a time can be evaluated. On the other hand, several factors can influence the outcome such as variation in pipetting technique, washing steps, ambient temperature, sample collection, and incubation time. However, including controls, series of standards and running samples in duplicate or triplicate provide sufficient data for statistical validation of the results.

\section{Quantitative real-time PCR}

To assess the expression level of the target genes, quantitative real-time PCR was employed via TaqMan ${ }^{\circledR}$ system. The principle of this technique is to quantify amplification of the DNA sequence of the gene of interest using target specific primers, Taq polymerase and a probe that is specific to the target region. The probe is an oligonucleotide in which a fluorescent reporter and quencher dye are attached to its 5 ' and $3^{\prime}$-ends, respectively. The quencher is designed to 
prevent emission of fluorescence in the unhybridized probe due to the proximity to the fluorescent end.

In brief, the target cell or tissue RNA was extracted and transcribed to the complementary DNA (cDNA) by reverse transcription enzyme. The cDNA was then amplified by TaqMan system where the specific probes would be hybridized to the internal region of cDNA. Following exonuclease activity of the Taq polymerase, the probe is cleaved resulting in the emission of light in each cycle by the fluorescent reporter. The emitted fluorescent signal is therefore proportional to the amount of new product.

The results obtained by RT-PCR can be quantified either with the standard curve method or the comparative cycle threshold $(\mathrm{Ct})$ method. In papers I and II, the comparative $\mathrm{Ct}$ method was employed by which the $\mathrm{Ct}$ value of the target samples were compared with the $\mathrm{Ct}$ value of their control. The $\mathrm{Ct}$ value is the point at which the fluorescent is measurable. The $\mathrm{Ct}$ values of the samples and controls were then normalized to a reference gene such as GAPDH.

The level of mRNA can be quantified via other commonly used techniques (i.e. northern blot analysis, RNase protection assay, end-point RT-PCR). However, none has the sensitivity and accuracy of qPCR. It is noteworthy that the amplification efficiency of the target samples and the reference gene in a qPCR analysis must be approximately equal to achieve high accuracy. Including serial dilution of the target cDNA allows comparison of their $\mathrm{Ct}$ values and check the amplification efficiency. 


\section{Paper I}

Fever is a brain adaptive response to pathogenic agents that occurs during inflammation. PGs have been shown to link systemic inflammation to brain adaptive responses ${ }^{261}$. Among PGs, $\mathrm{PGE}_{2}$ is an essential mediator in the pathogenesis of fever and upon an immune challenge, its synthesizing enzymes, COX-2 and mPGES-1, are expressed by many immune and nonimmune cells in the periphery and brain ${ }^{151,154,156,159,262}$. Within the brain, COX-2 is induced

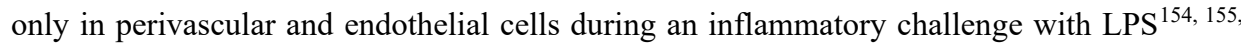
${ }^{220}$, but the cellular localization of pyrogenic $\mathrm{PGE}_{2}$ has not been fully determined. Hence, in our first study, we addressed the cellular source of pyrogenic $\mathrm{PGE}_{2}$ in the well-established model of LPS-induced inflammatory fever.

Using genetical tools for cell type-specific deletion of genes of interest ${ }^{263,264}$, we generated mice with selective deletion of COX-2 in the brain endothelial cells. Checking recombination efficiency in these mice revealed more than $85 \%$ deletion of COX-2 in the brain endothelium, but intact COX-2 expression in the periphery such as lung endothelial cells, indicating celltype specificity of the deletion.

To test our hypothesis that the brain endothelial cells are the cellular source of pyrogenic $\mathrm{PGE}_{2}$, mice with selective deletion of COX-2 in the brain endothelium were immune-challenged with IL-1 $\beta$. The results showed that the fever response was significantly attenuated in mice lacking COX-2 in the brain endothelium. Similar findings were observed when the immune stimulus was changed to LPS, indicating that brain endothelial COX-2 plays pivotal role in inflammation-induced fever.

We further examined whether COX-2 in the brain endothelium mediates other aspects of sickness behavior such as lethargy. Therefore, the locomotor activity of mice lacking COX-2 in the brain endothelial cells was investigated upon immune challenge with IL-1 $\beta$. Interestingly, the locomotor activity in mice with selective deletion of COX-2 in the brain endothelial cells was not affected, implying that brain endothelial COX-2 is not involved in the inhibition of locomotor activity. It seems that the brain endothelial COX-2 plays key role in the induction of inflammatory fever, but not other aspects of sickness behavior such as lethargy 
Our findings were in line with a previous study in which selective deletion of IL-1 receptors in brain endothelial cells resulted in a significant attenuation of the febrile response in mice immune challenged with IL- $1 \beta^{265}$. Although their findings suggested a role of brain endothelial cells in inflammation-induced fever, it did not elaborate the role of pyrogenic $\mathrm{PGE}_{2}$ as the essential mediator for the febrile response. The pyrogenic effect of IL-1 $\beta$, on the other hand, has been shown to require the expression of COX-2, as fever was blunted in COX-2 knock-out animals that were intraperitoneally administrated with IL-1 $\beta^{266}$. Our findings for the first time showed that the brain endothelium plays key role in induction of fever response via expression of COX-2 that is a necessary downstream event for mediating an inflammatory fever.

To further confirm that the blunted fever response observed was due to the lack of brain endothelial COX-2, and not to a blunted inflammatory process in the periphery, the plasma level of IL-1 $\beta$ in mice with selective deletion of COX-2 in the brain endothelium was detected after immune challenge with LPS. The plasma level of IL-1 $\beta$ was significantly elevated upon LPS challenge in both WT and mutant mice, which was a strong evidence of an intact inflammatory response in the mutant mice.

In addition to that, we checked whether the recombination of COX-2 gene in the brain endothelium affected the activation of other endothelial cells in the periphery and if the brain endothelium activity is influenced when COX-2 is deleted. To detect endothelial activation we used lipocalin-2 as a marker ${ }^{101}$. We observed that upon immune challenge with LPS, not only peripheral endothelial cells, but also the brain endothelium display remarked expression of lipocalin-2. These data revealed that the attenuated fever response observed in these mice was not due to a blunted inflammatory response or lack of endothelial cell activation, but to absence of the brain endothelial COX-2.

To support these findings, the expression level of other genes such as Cebpd, $\mathrm{Ccl} 2$ and $\mathrm{Cxcl10}$ which were shown to be highly induced in the hypothalamus upon immune challenge ${ }^{267}$, were also identified. The results confirmed that both WT and mutant mice showed similar degree of hypothalamic gene expression of these inflammatory components.

Given that the last step in the production of pyrogenic $\mathrm{PGE}_{2}$ is mediated by mPGES-1 ${ }^{107}$, we generated mice that lacks mPGES-1 in the brain endothelium and examined the febrile response in these mice when immune challenged with LPS. The results showed that the febrile response in the corresponding mice, similar to mice lacking brain endothelial COX-2, was significantly 
attenuated. Taken together, our findings, for the first time, revealed that the brain endothelial $\mathrm{PGE}_{2}$ synthesis plays a pivotal role in the induction of inflammatory fever.

It should be noted that, although there was a significant attenuation of the febrile response in mice with selective deletion of brain endothelial $\mathrm{COX}-2$, the febrile response was not fully abolished in these mice. The residual fever response observed in these mice might be from the COX-2 originated from macrophages in the periphery or perivascular cells within the brain ${ }^{154}$, ${ }^{155,164}$. However, it has been shown that the fever response was not dependent on the expression of mPGES-1 by macrophages or perivascular cells ${ }^{165}$.

Given that mice with global deletion of COX-2 or mPGES-1 as well as WT mice treated with pharmacological inhibitor for COX-2 showed completely blunted fever responses ${ }^{100,150,151,165}$, the residual fever observed in our mice may result from residual COX-2 which was not affected by the gene interference technology. As mentioned earlier, the recombination efficiency of COX-2 in the hypothalamus of the corresponding mice was not complete and there were sparse endothelial cells that induced COX-2 upon immune challenge. The residual fever could also be dependent on COX-2 in non-endothelial cells. 


\section{Paper II}

In the first study, we demonstrated that brain endothelial $\mathrm{PGE}_{2}$ synthesis is necessary for the febrile response. However, the mechanism by which $\mathrm{PGE}_{2}$ is induced in the brain endothelial cells remains obscure. Pyrogenic cytokines such as IL-6 are believed to signal the brain and initiate the fever response, since mice given neutralizing antibody against IL- 6 or mice with global deletion of IL-6 showed a blunted fever response ${ }^{100,268}$. However, the mechanism by which the peripherally produced IL-6 induces fever is also not fully understood. Hence, we examined the contribution of IL-6 receptors on different cell-types in inflammation-induced fever.

As the membrane bound receptor of IL- 6 is expressed by several cell types in the nervous system $^{196,269}$, we generated mice with selective deletion of IL-6R $\alpha$ in brain endothelial cells, neural cells (neurons and glia) and primary afferents and immune challenged them with LPS. Mice with selective deletion of IL-6R $\alpha$ in the neural cells and peripheral sensory neurons showed intact febrile responses, whereas a significant attenuation of fever responses was observed in mice with selective deletion of IL-6R $\alpha$ in the brain endothelial cells.

To verify the recombination efficiency, the hypothalamic expression of IL-6R $\alpha$ in these mice were analyzed. As expected, the expression of IL-6R $\alpha$ in the hypothalamus of mice with selective deletion of brain endothelium IL-6R $\alpha$ was markedly attenuated.

We further examined whether the attenuated febrile response in mice with selective deletion of brain endothelium IL-6R $\alpha$ is associated to the hypothalamic induction of COX-2. We observed that the mice lacking IL-6R $\alpha$ in the brain endothelium displayed a significant reduction in the hypothalamic induction of COX-2 when immune challenged with LPS. Thus, the attenuation of fever in mice with the brain endothelium IL-6R $\alpha$ deletion is likely due to the reduced induction of COX-2 in the brain endothelial cells.

Our findings suggest that the pyrogenic effect of IL- 6 is exerted by induction of COX-2 in the brain endothelial cells. This is in line with the study showing that mice treated with neutralizing antibody against IL-6 displayed blunted fever response with attenuated cerebral COX-2 after immune challenge with LPS ${ }^{268}$. Although, in another study in which IL-6 knockout mice were immune challenged with LPS, the cerebral and plasma level of $\mathrm{PGE}_{2}$ were elevated. The $\mathrm{PGE}_{2}$ in IL-6 knockout mice could be released from another source by which act as compensatory mechanism in these mutant mice ${ }^{100}$. 
To support the role of IL-6R and its intracellular signaling in the induction of fever, we generated mice with selective deletion of the brain endothelium STAT-3, which is a downstream transcription factor in the IL-6R $\alpha$ intracellular signaling pathway ${ }^{83}$. These mice, similar to mice with selective deletion of IL-6R $\alpha$ in the brain endothelial cells, displayed a significantly attenuated fever response.

We also examined whether mice lacking IL-6R $\alpha$ in the brain endothelial cells have an intact inflammatory response. Therefore, the hypothalamic activation of $\mathrm{NF \kappa B}$ was analyzed in these mice. WT and mutant mice showed similar level of NFKB activation in the hypothalamus, implying that the deletion of brain endothelial IL-6R had no effect on general inflammatory mechanisms in the hypothalamus.

IL-6, unlike IL-1 $\beta$, has been shown to pose a very weak pyrogenic potency ${ }^{270,} 271$. Intraperitoneal injection of IL-6 is unable to induce cerebral COX-2 and generate fever. However, when IL-6 is combined with a nonpyrogenic dose of IL-1 $\beta$, it evokes fever ${ }^{100,270,271}$. LPS-induced inflammation results in concurrent release of IL-1 $\beta$ and IL- $6^{272}$ and it is likely that they together trigger the induction of pyrogenic COX-2 in the brain endothelium. The induction of COX-2 via activation of the p38 MAPK and STAT-3 pathway ${ }^{264,268}$, implies the synergic action of IL-1 $\beta$ and IL-6 signaling in the generation of inflammation-induced fever response. Therefore, the attenuated fever response due to the lack of IL-6R $\alpha$ on the brain endothelial cells that were shown in our study, is one of the pathways in which the pyrogenic COX-2 is induced.

Although, our results showed that the fever response was markedly attenuated in mice with selective deletion of IL-6R $\alpha$ in the brain endothelium, the febrile response was not completely blunted in response to LPS. As reported in our first study, despite high deletion efficiency in mice with selective deletion of brain endothelium COX-2, the recombinase failed to be induced in all endothelial cells. The remaining intact endothelial cells (about 15\%) may account for the residual fever that was observed in these mice. Alternatively, another cell type is involved.

Another possibility is that the soluble form of IL-6R that circulates in the body and shares the common intracellular signaling pathway with membrane bound IL-6 $\mathrm{R}^{273}$, can drive the residual fever that was observed in the corresponding mice. The soluble IL-6 poses proinflammatory potency and therefore unable to promote inflammatory response by most neuronal types, endothelial cells, oligodendrocytes and many other cell types expressing gp $130^{274}$. However, the fact that deletion of the IL- 6 receptor and the deletion of STAT-3 result in similar 
attenuations of the febrile response indicate that soluble IL-6 receptors do not contribute to pyrogenic IL-6 signaling in brain endothelial cells.

The fever response was previously suggested to be induced by the activation of peripheral nerves in the model of localized inflammation induced by LPS $^{214}$. However, in our experimental paradigm, mice lacking IL-6R $\alpha$ in the primary sensory ganglia displayed an intact fever response, indicating that LPS-induced fever is not mediated through the activation of IL$6 \mathrm{R}$ signaling in the peripheral nerves.

Moreover, our findings are consistent with previous studies, demonstrating that intracerebroventricularly administration of IL-6 resulted in the elevation of COX-2 expression and generated a fever response ${ }^{99,275}$. The administrated IL-6 into the cerebroventricular system most likely binds to IL-6R on the brain endothelial cells. In a similar way, we propose that the peripheral IL-6, released during an inflammatory response, reaches areas surrounding the sensory circumventricular organs and the MnPO where it binds to its ligand on the brain endothelial cells to induce COX-2 expression and generates fever. 


\section{Paper III}

Paracetamol is one of the most widely used antipyretic medicine in the clinical setting. Apart from being antipyretic, it also induces hypothermia if given in higher dose $\mathrm{e}^{253}$. The hypothermic effect of paracetamol, has been shown to be dependent on TRPA1, a transient thermo receptor that senses noxious cold ${ }^{254}$. TRPA1 has also been reported to mediate the analgesic effect of paracetamol via NAPQI which is a reactive metabolite of paracetamol ${ }^{252}$. Given the role of TRPA1 in the hypothermic and analgesic effects of paracetamol, we examined the possible role of this ion channel in the antipyretic action of paracetamol.

To identify doses of paracetamol that did and did not induce hypothermia, different doses of paracetamol were administrated to WT mice. Our results showed that paracetamol in dose of $200 \mathrm{mg} / \mathrm{kg}$ is hypothermic which was consistent with other studies reporting 160 or $300 \mathrm{mg} / \mathrm{kg}$ of paracetamol induce hypothermic response in WT mice ${ }^{254,276}$. The hypothermic dose (200 $\mathrm{mg} / \mathrm{kg}$ ) was then applied in TRPAl knockout mice where the results confirmed that hypothermic effect of paracetamol is TRPA1-dependent, as reported by Gentry and collaborators $^{254}$.

In line with the study showing that activation of TRPA1 by NAPQI mediates the analgesic effect of paracetamol ${ }^{252}$, we examined whether the TRPA1-dependent hypothermic effect of paracetamol is also mediated via NAPQI. Our results displayed that the hypothermic dose of paracetamol in mice pretreated with NAPQI-replenishing metabolite, NAC ${ }^{277}$, protects WT mice from hypothermia. These findings indicate that the hypothermic effect of paracetamol, similar to its analgesic effect, is mediated by NAPQI activating TRPA1 ion channel.

To examine the possible role of TRPA1 in the antipyretic effect of paracetamol, subhypothermic dose of paracetamol was administrated to WT and TRPA1 knockout mice that were previously immune challenged with LPS. As $150 \mathrm{mg} / \mathrm{kg}$ of paracetamol did not induce hypothermia in our WT mice and this dose was previously shown to exert analgesic effect ${ }^{251}$, 278, we selected this dose as an antipyretic dose. Febrile TRPA1 knockout mice given the antipyretic dose of paracetamol displayed similar temperature response as their WT counterparts, indicating that the antipyretic effect of paracetamol is not TRPA1-dependent. Although, another study in a model of LPS-induced inflammatory pain showed that the sensitization of nociceptors is mediated through direct activation of TRPA1 by LPS ${ }^{279}$, our study, in contrary, showed that LPS-induced inflammatory fever occurs independent of TRPA1 activation. 
Other studies reported that subcutaneous administration of $300 \mathrm{mg} / \mathrm{kg}$ or intravenous injection of $160 \mathrm{mg} / \mathrm{kg}$ of paracetamol induced hypothermia ${ }^{254,276}$. However, no temperature changes were reported when paracetamol was given intrathecally in a dose of $100 \mathrm{mg} / \mathrm{kg}^{254}$. In our study, intraperitoneal administration of $150 \mathrm{mg} / \mathrm{kg}$ paracetamol did not induce hypothermic response in the non-immune challenged WT mice. However, this sub-hypothermic dose of paracetamol induced profound hypothermia in the febrile WT mice, but not in the febrile TRPA1 knockout mice.

The sensitivity of the febrile WT to the sub-hypothermic dose of paracetamol in our experiment was assumed to be due to the presence of TRPA1 ion channel, as the hypothermic response was not observed in the febrile TRPA1 knockout mice. To test our hypothesis, the febrile mice from both groups were given another antipyretic compound which is a selective COX-2 inhibitor, parecoxib. The results confirmed that the sensitivity of the febrile mice to the subhypothermic dose of paracetamol was indeed due to the activation of TRPA1 in the WT mice, as the hypothermic response observed with the sub-hypothermic dose of paracetamol in the febrile WT mice was completely abolished with parecoxib treatment in both febrile WT and TRPA1 knockout mice.

The free radicals and peroxides produced during an inflammatory condition such as fever are required to be detoxified by glutathione which exists in the physiological system ${ }^{280}$. In addition to that, paracetamol treatment can result in the production of more toxic metabolites such as $\mathrm{NAPQI}^{245}$, which can exceed the capacity of glutathione system to detoxify it.

We examined the role of NAPQI in the hypothermic response to paracetamol by another experiment in which the febrile WT mice were administrated NAC prior to administration of the sub-hypothermic dose of paracetamol. The results showed that administration of NAC prevented the hypothermic response, indicating that the increased sensitivity of the febrile WT mice to even sub-hypothermic dose of paracetamol is most likely due to the activation of TRPA1 by the paracetamol metabolite, NAPQI.

Following our preliminary findings in which the antipyretic effect of paracetamol is not TRPA1-dependant and based on earlier studies on antipyretic action of paracetamol in inhibition of PGs synthesis $228,276,281$, we investigated the level of prostanoids in the blood and brain of the febrile mice treated with the sub-hypothermic dose of paracetamol. Interestingly, our results demonstrated that paracetamol not only attenuated the level of $\mathrm{PGE}_{2}$ in the brain, it also suppressed the brain level of other prostanoids such as $\mathrm{TXB}_{2}, \mathrm{PGF}_{2 \mathrm{a}}$ and $\mathrm{PGF}_{1 \mathrm{a}}$. These 
findings were consistent with previous studies suggesting that paracetamol exerts its antipyretic effect by inhibition of PGs synthesis in the brain ${ }^{228}$.

Studies on the antipyretic role of paracetamol in the model of LPS-induced inflammatory fever have also shown that paracetamol blocks the pyrogenic action of $\mathrm{PGE}_{2}$ and that it normalizes the elevated body temperature and brain $\mathrm{PGE}_{2}$ levels which are induced by LPS $276,281$. Although, paracetamol did not seem to affect the plasma level of $\mathrm{PGE}_{2}$ and only attenuated the brain $\mathrm{PGE}_{2}{ }^{276}$, the level of PGE2 in the blood of our febrile mice treated with paracetamol was below detection limit. This could result from the timepoint that was chosen for harvesting the brain and blood.

Studies on paracetamol have revealed that its antipyretic mode of action is mainly exerted by inhibition of COX-2 $2^{233}$. Paracetamol has been shown to inhibit inducible COX-2 in the brain, but not peripheral inducible COX-2, which explains its poor anti-inflammatory property ${ }^{282}$.

As our first paper in this thesis showed that fever is mediated by the brain endothelium $\mathrm{PGE}_{2}$ and that paracetamol is also shown to target the inducible COX-2 in the brain ${ }^{237,276}$, it is likely that the antipyretic effect of paracetamol is exerted by inhibition of $\mathrm{PGE}_{2}$ in the cerebral vasculature where the expression of COX-2 in upregulated upon LPS challenge ${ }^{237}$.

Although, paracetamol was shown to not inhibit the peripheral COX $-1^{282}$, the general suppression of prostanoid levels in the brain that was seen in our present study indicates the involvement of both COX-1 and COX-2 in the antipyretic action of paracetamol. Consistent with this finding, the expression of brain $\mathrm{PGE}_{2}$ was shown to be suppressed by paracetamol in the WT mice without being immune challenged ${ }^{283}, 284$, implying the effect of paracetamol on not only inducible, also on constitute level of $\mathrm{PGE}_{2}$. 
$\mathrm{PGE}_{2}$ produced in the brain is an essential mediator in the generation of fever. However, its cellular localization and the mechanism of its induction have not been fully elucidated. In this thesis, we showed that fever is dependent on $\mathrm{PGE}_{2}$ synthesizing enzymes, COX-2, and mPGES-1, in the brain endothelial cells, implying the essential role of brain endothelial $\mathrm{PGE}_{2}$ in the febrile response. We also demonstrated that activation of brain endothelial IL-6Rs mediate the induction of $\mathrm{PGE}_{2}$ (Fig.5). Our studies on the antipyretic effect of paracetamol revealed that unlike its hypothermic effect, its antipyretic effect is not dependent on TRPA1 receptors. Instead, the antipyretic effect of paracetamol is exerted by the inhibition of prostanoid synthesis in the brain. Taken together, these findings indicate that the brain endothelium acts as an interface in communication between the immune system and the brain in generation of fever.

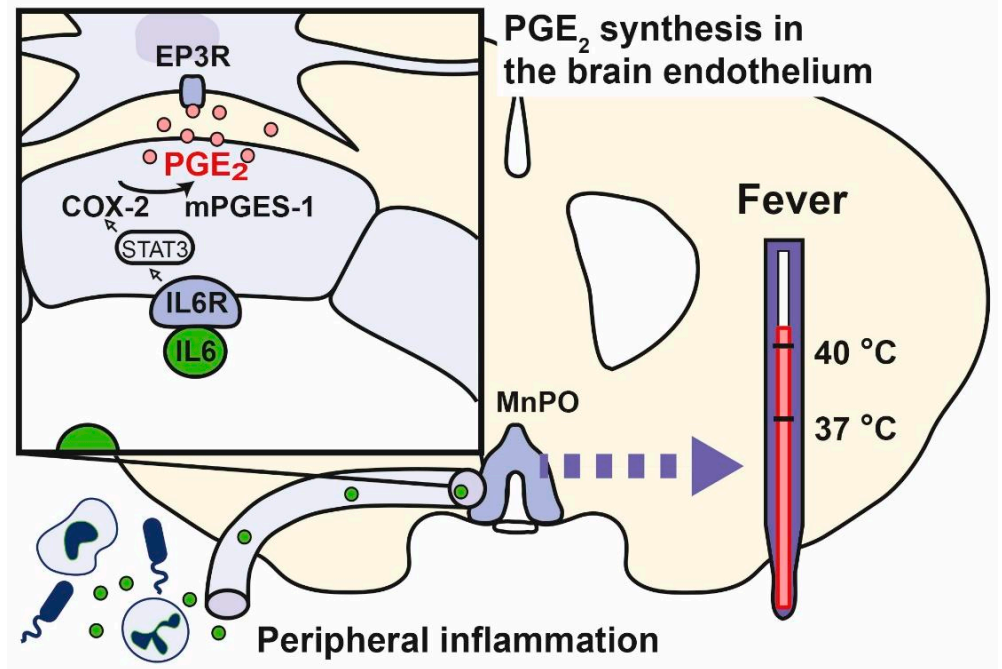

Figure 5. Summary of the fever induction by interleukin-6 in the preoptic hypothalamus. Peripherally released interleukin- 6 binds to its receptor on brain endothelial cells in the preoptic area and induce the induction of pyrogenic $\mathrm{PGE}_{2}$ by brain endothelial cells. The brain endothelium $\mathrm{PGE}_{2}$ elicits fever by binding to EP3 receptor expressing cells in the median preoptic nucleus. Modified from Blomqvist and Engblom $2018^{163}$. 


\section{Acknowledgments}

I would like to express my gratitude to all who contributed to this thesis:

Professor David Engblom, my supervisor. It has been a long journey since a summer day passing by your office and expressing my interest in "Immune-to-Brain Signaling" to join your group. I have learned so much from you and it has been fun to do several experiments with you in the animal facility, especially those popcorn EP3-KO mice. Your exceptional sense of humor, kindness and positivity make everything work. Thank you for being kind, supportive and simply a great supervisor!

Professor Anders Blomqvist, my respected co-supervisor. Your sharp analytical view, precision and deep knowledge are so impressive. Thank you for giving me the opportunity to be a part of your research projects and for being so supportive and understanding.

Professor Simin Mohseni, I am honored to have had you as my co-supervisor in the last years of my PhD. Thank you for your unconditional support and for being there for me in difficult times. You are one of the kindest people I know.

Professor Anders Fridberger, the head of department. Thank you for all support!

Daniel Wilhelms, you were the best colleague one could ask for. Thank you for believing in me and for supporting me in many aspects; from teaching me the details of a successful surgery to our fun conversations about non-scientific stuff! Remember the tattoo from bubbly chewing gum?!

Kiseko Shionoya, your enthusiasm and hard-working attitude are admirable. I have been lucky to learn microvascular surgery and stereotaxic procedure under your supervision. Thank you for the patience, knowledge, and expertise that you shared with me!

Professor Karin Öllinger, thank you for always having a warm smile and open arms. You are amazingly caring!

Katarina Kågedal, thank you for giving me the opportunity to teach in the "Scientific Methodology" course. Your family-centered spirit is contagious and helped me to take a break from work when I needed it by focusing on little Charlotte. Thanks for being an excellent coach!

Thanks to Anna Nilsson for being such a nice colleague and friend, Maarit Jaarola for valuable support during experiments and for cheering me up with fikas, Anna Eskilsson for fruitful collaborations, Unn Kugelberg for technical support and useful advice, Takashi Matsuwaki for believing in me and for your intercontinental support with surprise parcels!

Thanks to other nice members of our group: Joanna Zajdel, Andrea Stojakovic, Anand Kumar Singh, and Fredrik Ahlström for the fruitful collaborations outside of this thesis, also for being good friends, especially for the picnic times and the nutella party in the cave! 
Thanks to all the people at Cell Biology on floors 11 and 12 during these years: Professor Fredrik Elinder, Björn Granseth, Johan Brask, Sofi Sundberg, Nina Ottosson, Ulrika Englund, Sara Liin, Jakob Renhorn, Luca Conti, Gonzalo Manuel Sanches, Maryam Bagheri, Sajad Salari, Ayman Osman, Asif Aziz and Shadi Jafari.

Thanks to the kind staff of the animal facility: Petra and Björn Wolbert, Anna Fyrberg, Emma Egedal, Anders Delleskog, Annette Alexandersson, Anna-Carin Hagström, Albin Malm, Andreas Linghammar and Linda Bergström.

Thanks to all the nice people at floor 9 in Clinical Pathology: Professor Karin Roberg, Professor Jonas Broman, Linda Vainikka, Emilia Wiechec, Maria Ntzouni, Petra Wäster, Max Larsson, Ida Eriksson and Aida Vahdat. You all welcomed me as if I were part of your group, Thank you!

Mitra Habibi, for providing such a great support when I needed.

Hans, Claus and Mari, thanks for being there!

Thanks to Soltanpour family for hosting me in the beginning of my journey like my own parents, Fikouhi family for encouraging me, Gilaki family for all the joyful moments, they mean a lot to me!

Dr. Parviz Pakzad, thank you for believing in me and for all the valuable advice.

Family friends Birgit and Thomas, Erica and Marcus, Elmira, and Daniel, thank you all for the great gatherings and unforgettable moments!

Fredrik Dehner, you are an extraordinary human being and I was lucky to meet you. Thank you for listening to me, to call and support even when I was abroad. You know what you have done was more than I could have wished for. I appreciate it a lot!

Dr. Nermin Bilalovic, I am very grateful for all you have done for me. Thank you for knowing when and how to help. You cannot imagine how much comfort you have given me all these years!

Camilla, thank you for warming my heart and for being such a great friend. Your dignity is beyond description!

Professor Cyrus Aleseyed, my beloved uncle! Thank you for all the generous support you have given me these years. Your Sunday evening calls always washed away all the worries! Thanks for being Like a father to me!

Pouyan, thanks for great friendship, although our never-ending discussions would spice it up from time to time. Thanks for unlimited support!

My family in law: Christian for listening to me and sharing your experience in academia as a teacher, Kia and Birgitta for cheering me up and for reminding me that life exists outside of academia as well.

Pegah, best friend who became my sister. I am so grateful to have you in my life. Thanks for always being there for me! 
Elham, my sister. Your positivity reaches me even from another continent. Thank you for always being there for me and for your heart-warming words. You cannot imagine how your magic stick works!

Mom, your determination in all those years of teaching and studying at the same time has been a source of inspiration to me. You made me interested in physiology and anatomy by dissecting internal organs of ship, cow, or even small goldfish. Thank you for being an amazing Mother!

Dad, your social and management skills together with intelligence are exceptional. You have been my role mode since I was a little girl! You taught me how to plan and stay motivated. I could never make it without you, thanks a lot for being such a great father!

Andreas, my wonderful husband. I could never foresee to become your wife when I was your student in "Tumor Biology" course, nor having blessed with our little angel years later. Your patience, kind heart and wisdom have made me the person I am now. Thank you for always being at my side and for being my best friend and the love of my life!

Charlotte, min solstråle. You are the most valuable treasure! 


\section{References}

1. Cannon WB. The Wisdom of the Body W. W. Norton \& Company, inc. (1932).

2. Haroon E, Raison CL, Miller AH. Psychoneuroimmunology meets neuropsychopharmacology: translational implications of the impact of inflammation on behavior. Neuropsychopharmacology 37, 137-162 (2012).

3. Couzin-Frankel J. Inflammation bares a dark side. Science 330, 1621 (2010).

4. Aguilera G. HPA axis responsiveness to stress: implications for healthy aging. Exp Gerontol 46, 90-95 (2011).

5. Webster JI, Tonelli L, Sternberg EM. Neuroendocrine regulation of immunity. Annu Rev Immunol 20, 125-163 (2002).

6. Purves D AGJ, Fitzpatrick D, Hall W.C, Lamantia A.S, Mcnamara J.O, Williams S.M. NEUROSCIENCE, Third edn. Sinauer Associates, Inc (2004).

7. Cabanac M, Massonnet B. [Pathology of thermoregulation]. Rev Neurol (Paris) 136, 285-302 (1980).

8. Boulant JA, Gonzalez RR. The effect of skin temperature on the hypothalamic control of heat loss and heat production. Brain Res 120, 367-372 (1977).

9. Hammel HT. Regulation of internal body temperature. Annu Rev Physiol 30, 641-710 (1968).

10. Romanovsky AA. The thermoregulation system and how it works. Handb Clin Neurol 156, 3-43 (2018).

11. Nagashima K, Nakai S, Tanaka M, Kanosue K. Neuronal circuitries involved in thermoregulation. Auton Neurosci 85, 18-25 (2000).

12. Satinoff E, Rutstein J. Behavioral thermoregulation in rats with anterior hypothalamic lesions. J Comp Physiol Psychol 71, 77-82 (1970).

13. Nakamura K. Central circuitries for body temperature regulation and fever. Am J Physiol Regul Integr Comp Physiol 301, R1207-1228 (2011).

14. Morrison SF. Central neural control of thermoregulation and brown adipose tissue. Auton Neurosci 196, 14-24 (2016).

15. Wu L, Sweet TB, Clapham DE. International Union of Basic and Clinical Pharmacology. LXXVI. Current progress in the mammalian TRP ion channel family. Pharmacol Rev 62, 381-404 (2010).

16. McKemy DD, Neuhausser WM, Julius D. Identification of a cold receptor reveals a general role for TRP channels in thermosensation. Nature 416, 52-58 (2002).

17. Namer B, Seifert F, Handwerker HO, Maihofner C. TRPA1 and TRPM8 activation in humans: effects of cinnamaldehyde and menthol. Neuroreport 16, 955-959 (2005).

18. Smith GD, et al. TRPV3 is a temperature-sensitive vanilloid receptor-like protein. Nature 418, 186-190 (2002).

19. Watanabe H, Vriens J, Suh SH, Benham CD, Droogmans G, Nilius B. Heat-evoked activation of TRPV4 channels in a HEK293 cell expression system and in native mouse aorta endothelial cells. J Biol Chem 277, 47044-47051 (2002).

20. Caterina MJ, Schumacher MA, Tominaga M, Rosen TA, Levine JD, Julius D. The capsaicin receptor: a heat-activated ion channel in the pain pathway. Nature 389, 816-824 (1997).

21. Caterina MJ, Rosen TA, Tominaga M, Brake AJ, Julius D. A capsaicin-receptor homologue with a high threshold for noxious heat. Nature 398, 436-441 (1999).

22. Gupta BN, Nier K, Hensel H. Cold-sensitive afferents from the abdomen. Pflugers Arch 380, 203-204 (1979).

23. Boulant JA, Dean JB. Temperature receptors in the central nervous system. Annu Rev Physiol 48, 639654 (1986).

24. Craig AD, Krout K, Andrew D. Quantitative response characteristics of thermoreceptive and nociceptive lamina I spinothalamic neurons in the cat. J Neurophysiol 86, 1459-1480 (2001).

25. Riedel W. Warm receptors in the dorsal abdominal wall of the rabbit. Pflugers Arch 361, 205-206 (1976).

26. Nakamura K, Morrison SF. Preoptic mechanism for cold-defensive responses to skin cooling. J Physiol 586, 2611-2620 (2008).

27. Nakamura K, Morrison SF. A thermosensory pathway mediating heat-defense responses. Proc Natl Acad Sci U S A 107, 8848-8853 (2010).

28. Hylden JL, Anton F, Nahin RL. Spinal lamina I projection neurons in the rat: collateral innervation of parabrachial area and thalamus. Neuroscience 28, 27-37 (1989). 
29. Craig $A D$, Bushnell $M C$, Zhang ET, Blomqvist A. A thalamic nucleus specific for pain and temperature sensation. Nature 372, 770-773 (1994).

30. Andrew D, Craig AD. Spinothalamic lamina I neurones selectively responsive to cutaneous warming in cats. J Physiol 537, 489-495 (2001).

31. Nakamura K, Morrison SF. A thermosensory pathway that controls body temperature. Nat Neurosci 11, 62-71 (2008).

32. Bratincsak A, Palkovits M. Activation of brain areas in rat following warm and cold ambient exposure. Neuroscience 127, 385-397 (2004).

33. Nakayama T, Eisenman JS, Hardy JD. Single unit activity of anterior hypothalamus during local heating. Science 134, 560-561 (1961).

34. Boulant JA, Hardy JD. The effect of spinal and skin temperatures on the firing rate and thermosensitivity of preoptic neurones. J Physiol 240, 639-660 (1974).

35. Boulant JA. The effect of firing rate on preoptic neuronal thermosensitivity. J Physiol 240, 661-669 (1974).

36. Tanaka M, McKinley MJ, McAllen RM. Roles of two preoptic cell groups in tonic and febrile control of rat tail sympathetic fibers. Am J Physiol Regul Integr Comp Physiol 296, R1248-1257 (2009).

37. Yu S, et al. Glutamatergic Preoptic Area Neurons That Express Leptin Receptors Drive TemperatureDependent Body Weight Homeostasis. J Neurosci 36, 5034-5046 (2016).

38. Tan CL, et al. Warm-Sensitive Neurons that Control Body Temperature. Cell 167, 47-59 e15 (2016).

39. Abbott SBG, Saper CB. Median preoptic glutamatergic neurons promote thermoregulatory heat loss and water consumption in mice. J Physiol 595, 6569-6583 (2017).

40. Dimicco JA, Zaretsky DV. The dorsomedial hypothalamus: a new player in thermoregulation. Am J Physiol Regul Integr Comp Physiol 292, R47-63 (2007).

41. Morrison SF, Nakamura K. Central neural pathways for thermoregulation. Front Biosci (Landmark Ed) 16, 74-104 (2011).

42. Morrison SF, Madden CJ. Central nervous system regulation of brown adipose tissue. Compr Physiol 4, 1677-1713 (2014).

43. Nakamura K, Morrison SF. Central efferent pathways for cold-defensive and febrile shivering. J Physiol 589, 3641-3658 (2011).

44. Eberl G. Immunity by equilibrium. Nat Rev Immunol 16, 524-532 (2016).

45. Marques RE, Marques PE, Guabiraba R, Teixeira MM. Exploring the Homeostatic and Sensory Roles of the Immune System. Front Immunol 7, 125 (2016).

46. Akira S, Uematsu S, Takeuchi O. Pathogen recognition and innate immunity. Cell 124, 783-801 (2006).

47. Takeuchi O, Akira S. Pattern recognition receptors and inflammation. Cell 140, 805-820 (2010).

48. Lamkanfi M, Dixit VM. Manipulation of host cell death pathways during microbial infections. Cell Host Microbe 8, 44-54 (2010).

49. Janeway CA, Jr., Medzhitov R. Innate immune recognition. Annu Rev Immunol 20, 197-216 (2002).

50. Kushner I, Ganapathi M, Schultz D. The acute phase response is mediated by heterogeneous mechanisms. Ann N Y Acad Sci 557, 19-29; discussion 29-30 (1989).

51. Kumar H, Kawai T, Akira S. Pathogen recognition by the innate immune system. Int Rev Immuno/ 30, 1634 (2011).

52. O'Neill LA, Golenbock D, Bowie AG. The history of Toll-like receptors - redefining innate immunity. Nat Rev Immunol 13, 453-460 (2013).

53. Gewurz H, Mold C, Siegel J, Fiedel B. C-reactive protein and the acute phase response. Adv Intern Med 27, 345-372 (1982).

54. Atkins E. Fever: the old and the new. J Infect Dis 149, 339-348 (1984).

55. Dinarello CA, Renfer L, Wolff SM. Human leukocytic pyrogen: purification and development of a radioimmunoassay. Proc Natl Acad Sci U S A 74, 4624-4627 (1977).

56. Dinarello CA. Overview of the IL-1 family in innate inflammation and acquired immunity. Immunol Rev 281, 8-27 (2018).

57. Puren AJ, Fantuzzi G, Dinarello CA. Gene expression, synthesis, and secretion of interleukin 18 and interleukin 1 beta are differentially regulated in human blood mononuclear cells and mouse spleen cells. Proc Natl Acad Sci U S A 96, 2256-2261 (1999).

58. Berda-Haddad $\mathrm{Y}$, et al. Sterile inflammation of endothelial cell-derived apoptotic bodies is mediated by interleukin-1alpha. Proc Natl Acad Sci U S A 108, 20684-20689 (2011). 
59. Werman A, et al. The precursor form of IL-1alpha is an intracrine proinflammatory activator of transcription. Proc Natl Acad Sci U S A 101, 2434-2439 (2004).

60. Di Paolo NC, Shayakhmetov DM. Interleukin 1alpha and the inflammatory process. Nat Immunol 17, 906-913 (2016).

61. Cohen I, et al. Differential release of chromatin-bound IL-1alpha discriminates between necrotic and apoptotic cell death by the ability to induce sterile inflammation. Proc Natl Acad Sci U S A 107, 25742579 (2010).

62. Kurt-Jones EA, Beller DI, Mizel SB, Unanue ER. Identification of a membrane-associated interleukin 1 in macrophages. Proc Natl Acad Sci U S A 82, 1204-1208 (1985).

63. Hurgin V, Novick D, Werman A, Dinarello CA, Rubinstein M. Antiviral and immunoregulatory activities of IFN-gamma depend on constitutively expressed IL-1alpha. Proc Natl Acad Sci U S A 104, 5044-5049 (2007).

64. Dinarello CA. Interleukin-1 in the pathogenesis and treatment of inflammatory diseases. Blood 117, 3720-3732 (2011).

65. Brough D, Rothwell NJ. Caspase-1-dependent processing of pro-interleukin-1beta is cytosolic and precedes cell death. J Cell Sci 120, 772-781 (2007).

66. Coeshott $\mathrm{C}$, et al. Converting enzyme-independent release of tumor necrosis factor alpha and IL-1beta from a stimulated human monocytic cell line in the presence of activated neutrophils or purified proteinase 3. Proc Natl Acad Sci U S A 96, 6261-6266 (1999).

67. Gay NJ, Keith FJ. Drosophila Toll and IL-1 receptor. Nature 351, 355-356 (1991).

68. O'Neill LA, Bowie AG. The family of five: TIR-domain-containing adaptors in Toll-like receptor signalling. Nat Rev Immunol 7, 353-364 (2007).

69. Martin MU, Wesche H. Summary and comparison of the signaling mechanisms of the Toll/interleukin1 receptor family. Biochim Biophys Acta 1592, 265-280 (2002).

70. Weber A, Wasiliew P, Kracht M. Interleukin-1 (IL-1) pathway. Sci Signal 3, cm1 (2010).

71. Netea MG, et al. Differential requirement for the activation of the inflammasome for processing and release of IL-1beta in monocytes and macrophages. Blood 113, 2324-2335 (2009).

72. Garlanda C, Dinarello CA, Mantovani A. The interleukin-1 family: back to the future. Immunity 39, 10031018 (2013).

73. Mantovani A, Cassatella MA, Costantini C, Jaillon S. Neutrophils in the activation and regulation of innate and adaptive immunity. Nat Rev Immunol 11, 519-531 (2011).

74. Hoffmann E, et al. MEK1-dependent delayed expression of Fos-related antigen-1 counteracts c-Fos and p65 NF-kappaB-mediated interleukin-8 transcription in response to cytokines or growth factors. J Biol Chem 280, 9706-9718 (2005).

75. Nakao S, Ogata Y, Shimizu-Sasaki E, Yamazaki M, Furuyama S, Sugiya H. Activation of NFkappaB is necessary for IL-1beta-induced cyclooxygenase-2 (COX-2) expression in human gingival fibroblasts. Mol Cell Biochem 209, 113-118 (2000).

76. Milton AS, Wendlandt S. A possible role for prostaglandin E1 as a modulator for temperature regulation in the central nervous system of the cat. J Physiol 207, 76P-77P (1970).

77. Bernton EW, Beach JE, Holaday JW, Smallridge RC, Fein HG. Release of multiple hormones by a direct action of interleukin-1 on pituitary cells. Science 238, 519-521 (1987).

78. Vasilache AM, Qian H, Blomqvist A. Immune challenge by intraperitoneal administration of lipopolysaccharide directs gene expression in distinct blood-brain barrier cells toward enhanced prostaglandin E(2) signaling. Brain Behav Immun 48, 31-41 (2015).

79. Kishimoto T, Akira S, Narazaki M, Taga T. Interleukin-6 family of cytokines and gp130. Blood 86, 12431254 (1995).

80. Kishimoto T, Akira S, Taga T. Interleukin-6 and its receptor: a paradigm for cytokines. Science 258, 593597 (1992).

81. Narazaki $\mathrm{M}$, et al. Soluble forms of the interleukin-6 signal-transducing receptor component gp130 in human serum possessing a potential to inhibit signals through membrane-anchored gp130. Blood 82, 1120-1126 (1993).

82. Taga T, Kishimoto T. Gp130 and the interleukin-6 family of cytokines. Annu Rev Immunol 15, 797-819 (1997).

83. Heinrich PC, Behrmann I, Haan S, Hermanns HM, Muller-Newen G, Schaper F. Principles of interleukin (IL)-6-type cytokine signalling and its regulation. Biochem J 374, 1-20 (2003).

84. Hunter CA, Jones SA. IL-6 as a keystone cytokine in health and disease. Nat Immunol 16, 448-457 (2015). 
85. Naka T, et al. Structure and function of a new STAT-induced STAT inhibitor. Nature 387, 924-929 (1997).

86. Schmitz J, Weissenbach M, Haan S, Heinrich PC, Schaper F. SOCS3 exerts its inhibitory function on interleukin-6 signal transduction through the SHP2 recruitment site of gp130. J Biol Chem 275, 1284812856 (2000).

87. Hirano $\mathrm{T}$, et al. Purification to homogeneity and characterization of human B-cell differentiation factor (BCDF or BSFp-2). Proc Natl Acad Sci U S A 82, 5490-5494 (1985).

88. Hirano $\mathrm{T}$, et al. Complementary DNA for a novel human interleukin (BSF-2) that induces B lymphocytes to produce immunoglobulin. Nature 324, 73-76 (1986).

89. Weissenbach J, et al. Two interferon mRNAs in human fibroblasts: in vitro translation and Escherichia coli cloning studies. Proc Natl Acad Sci U S A 77, 7152-7156 (1980).

90. Heinrich PC, Castell JV, Andus T. Interleukin-6 and the acute phase response. Biochem J 265, 621-636 (1990).

91. Gillmore JD, Lovat LB, Persey MR, Pepys MB, Hawkins PN. Amyloid load and clinical outcome in AA amyloidosis in relation to circulating concentration of serum amyloid A protein. Lancet 358, 24-29 (2001).

92. Gauldie J, Richards C, Harnish D, Lansdorp P, Baumann H. Interferon beta 2/B-cell stimulatory factor type 2 shares identity with monocyte-derived hepatocyte-stimulating factor and regulates the major acute phase protein response in liver cells. Proc Natl Acad Sci U S A 84, 7251-7255 (1987).

93. Andus $\mathrm{T}$, et al. Recombinant human B cell stimulatory factor 2 (BSF-2/IFN-beta 2) regulates betafibrinogen and albumin mRNA levels in Fao-9 cells. FEBS Lett 221, 18-22 (1987).

94. Nemeth E, et al. IL-6 mediates hypoferremia of inflammation by inducing the synthesis of the iron regulatory hormone hepcidin. J Clin Invest 113, 1271-1276 (2004).

95. Ishibashi T, et al. Interleukin-6 is a potent thrombopoietic factor in vivo in mice. Blood 74, 1241-1244 (1989).

96. Mangan PR, et al. Transforming growth factor-beta induces development of the $\mathrm{T}(\mathrm{H}) 17$ lineage. Nature 441, 231-234 (2006).

97. Bettelli E, et al. Reciprocal developmental pathways for the generation of pathogenic effector TH17 and regulatory T cells. Nature 441, 235-238 (2006).

98. Zheng $\mathrm{H}$, et al. Resistance to fever induction and impaired acute-phase response in interleukin-1 betadeficient mice. Immunity 3, 9-19 (1995).

99. Chai Z, Gatti S, Toniatti C, Poli V, Bartfai T. Interleukin (IL)-6 gene expression in the central nervous system is necessary for fever response to lipopolysaccharide or IL-1 beta: a study on IL-6-deficient mice. J Exp Med 183, 311-316 (1996).

100. Nilsberth C, et al. The role of interleukin-6 in lipopolysaccharide-induced fever by mechanisms independent of prostaglandin E2. Endocrinology 150, 1850-1860 (2009).

101. Hamzic N, et al. Interleukin-6 primarily produced by non-hematopoietic cells mediates the lipopolysaccharide-induced febrile response. Brain Behav Immun 33, 123-130 (2013).

102. Kozak W, et al. IL-6 and IL-1 beta in fever. Studies using cytokine-deficient (knockout) mice. Ann $N Y$ Acad Sci 856, 33-47 (1998).

103. Smyth EM, Grosser T, Wang M, Yu Y, FitzGerald GA. Prostanoids in health and disease. J Lipid Res $\mathbf{5 0}$ Suppl, S423-428 (2009).

104. Clark JD, et al. A novel arachidonic acid-selective cytosolic PLA2 contains a $\mathrm{Ca}(2+)$-dependent translocation domain with homology to PKC and GAP. Cell 65, 1043-1051 (1991).

105. Hemler M, Lands WE. Purification of the cyclooxygenase that forms prostaglandins. Demonstration of two forms of iron in the holoenzyme. J Biol Chem 251, 5575-5579 (1976).

106. Rouzer CA, Marnett LJ. Cyclooxygenases: structural and functional insights. J Lipid Res 50 Suppl, S29-34 (2009).

107. Jakobsson PJ, Thoren S, Morgenstern R, Samuelsson B. Identification of human prostaglandin E synthase: a microsomal, glutathione-dependent, inducible enzyme, constituting a potential novel drug target. Proc Natl Acad Sci U S A 96, 7220-7225 (1999).

108. Beuckmann CT, Fujimori K, Urade Y, Hayaishi O. Identification of mu-class glutathione transferases M22 and M3-3 as cytosolic prostaglandin E synthases in the human brain. Neurochem Res 25, 733-738 (2000).

109. Thoren S, Jakobsson PJ. Coordinate up- and down-regulation of glutathione-dependent prostaglandin E synthase and cyclooxygenase-2 in A549 cells. Inhibition by NS-398 and leukotriene C4. Eur J Biochem 267, 6428-6434 (2000). 
110. Tanioka T, Nakatani Y, Semmyo N, Murakami M, Kudo I. Molecular identification of cytosolic prostaglandin E2 synthase that is functionally coupled with cyclooxygenase-1 in immediate prostaglandin E2 biosynthesis. J Biol Chem 275, 32775-32782 (2000).

111. Reddy ST, Herschman HR. Prostaglandin synthase-1 and prostaglandin synthase-2 are coupled to distinct phospholipases for the generation of prostaglandin D2 in activated mast cells. J Biol Chem 272, 3231-3237 (1997).

112. Naraba $\mathrm{H}$, et al. Segregated coupling of phospholipases A2, cyclooxygenases, and terminal prostanoid synthases in different phases of prostanoid biosynthesis in rat peritoneal macrophages. J Immunol 160, 2974-2982 (1998).

113. Legler DF, Bruckner M, Uetz-von Allmen E, Krause P. Prostaglandin E2 at new glance: novel insights in functional diversity offer therapeutic chances. Int J Biochem Cell Biol 42, 198-201 (2010).

114. Sugimoto $Y$, Narumiya S, Ichikawa A. Distribution and function of prostanoid receptors: studies from knockout mice. Prog Lipid Res 39, 289-314 (2000).

115. Sugimoto Y, Narumiya S. Prostaglandin E receptors. J Biol Chem 282, 11613-11617 (2007).

116. Moriyama T, et al. Sensitization of TRPV1 by EP1 and IP reveals peripheral nociceptive mechanism of prostaglandins. Mol Pain 1, 3 (2005).

117. Funk CD. Prostaglandins and leukotrienes: advances in eicosanoid biology. Science 294, 1871-1875 (2001).

118. Kawabe J, Ushikubi F, Hasebe N. Prostacyclin in vascular diseases. - Recent insights and future perspectives. Circ J 74, 836-843 (2010).

119. Bombardieri $\mathrm{S}$, et al. The synovial prostaglandin system in chronic inflammatory arthritis: differential effects of steroidal and nonsteroidal anti-inflammatory drugs. Br J Pharmacol 73, 893-901 (1981).

120. Noda $\mathrm{M}$, et al. Neuroprotective role of bradykinin because of the attenuation of pro-inflammatory cytokine release from activated microglia. J Neurochem 101, 397-410 (2007).

121. Urade Y, Hayaishi O. Prostaglandin D2 and sleep regulation. Biochim Biophys Acta 1436, 606-615 (1999).

122. Eguchi N, et al. Lack of tactile pain (allodynia) in lipocalin-type prostaglandin D synthase-deficient mice. Proc Natl Acad Sci U S A 96, 726-730 (1999).

123. Lewis RA, Soter NA, Diamond PT, Austen KF, Oates JA, Roberts LJ, 2nd. Prostaglandin D2 generation after activation of rat and human mast cells with anti-IgE. J Immunol 129, 1627-1631 (1982).

124. Basu S. Novel cyclooxygenase-catalyzed bioactive prostaglandin F2alpha from physiology to new principles in inflammation. Med Res Rev 27, 435-468 (2007).

125. Nakahata N. Thromboxane A2: physiology/pathophysiology, cellular signal transduction and pharmacology. Pharmacol Ther 118, 18-35 (2008).

126. Kalucka J, Bierhansl L, Wielockx B, Carmeliet P, Eelen G. Interaction of endothelial cells with macrophages-linking molecular and metabolic signaling. Pflugers Arch 469, 473-483 (2017).

127. Middleton J, Patterson AM, Gardner L, Schmutz C, Ashton BA. Leukocyte extravasation: chemokine transport and presentation by the endothelium. Blood 100, 3853-3860 (2002).

128. Sturtzel C. Endothelial Cells. Adv Exp Med Biol 1003, 71-91 (2017).

129. Vestweber D. How leukocytes cross the vascular endothelium. Nat Rev Immunol 15, 692-704 (2015).

130. Clark R, Kupper T. Old meets new: the interaction between innate and adaptive immunity. $J$ Invest Dermatol 125, 629-637 (2005).

131. Mehta D, Malik AB. Signaling mechanisms regulating endothelial permeability. Physiol Rev 86, 279-367 (2006).

132. Engelmann B, Massberg S. Thrombosis as an intravascular effector of innate immunity. Nat Rev Immunol 13, 34-45 (2013).

133. Konsman JP, Parnet P, Dantzer R. Cytokine-induced sickness behaviour: mechanisms and implications. Trends Neurosci 25, 154-159 (2002).

134. Hart BL. Biological basis of the behavior of sick animals. Neurosci Biobehav Rev 12, 123-137 (1988).

135. Johnson RW. The concept of sickness behavior: a brief chronological account of four key discoveries. Vet Immunol Immunopathol 87, 443-450 (2002).

136. Dantzer R. Cytokine-induced sickness behavior: where do we stand? Brain Behav Immun 15, 7-24 (2001).

137. Romanovsky AA. Thermoregulation: some concepts have changed. Functional architecture of the thermoregulatory system. Am J Physiol Regul Integr Comp Physiol 292, R37-46 (2007).

138. Dinarello CA PR. Harrison's Principles of Internal Medicine.). 20e edn. McGraw-Hill Education (2018).

139. Simon HB. Hyperthermia. N Engl J Med 329, 483-487 (1993). 
140. Oka T. Stress-induced hyperthermia and hypothermia. Handb Clin Neurol 157, 599-621 (2018).

141. Smith CJ, Johnson JM. Responses to hyperthermia. Optimizing heat dissipation by convection and evaporation: Neural control of skin blood flow and sweating in humans. Auton Neurosci 196, 25-36 (2016).

142. Romanovsky AA, Kulchitsky VA, Simons CT, Sugimoto N. Methodology of fever research: why are polyphasic fevers often thought to be biphasic? Am J Physiol 275, R332-338 (1998).

143. Romanovsky AA, et al. Fever and hypothermia in systemic inflammation: recent discoveries and revisions. Front Biosci 10, 2193-2216 (2005).

144. Rudaya AY, Steiner AA, Robbins JR, Dragic AS, Romanovsky AA. Thermoregulatory responses to lipopolysaccharide in the mouse: dependence on the dose and ambient temperature. Am J Physiol Regul Integr Comp Physiol 289, R1244-1252 (2005).

145. Vybiral S, Cerny L, Jansky L. Mode of ACTH antipyretic action. Brain Res Bull 21, 557-562 (1988).

146. Szelenyi Z. SM, Czippan L. Autonomic cold- and heat-defence of rats during a febrile rise in core temperature induced by intracerebroventricular infusion of prostaglandin E1. Pathophysiology 3, 8 (1996).

147. Romanovsky AA, Shido O, Sakurada S, Sugimoto N, Nagasaka T. Endotoxin shock: thermoregulatory mechanisms. Am J Physiol 270, R693-703 (1996).

148. Almeida MC, Steiner AA, Branco LG, Romanovsky AA. Cold-seeking behavior as a thermoregulatory strategy in systemic inflammation. Eur J Neurosci 23, 3359-3367 (2006).

149. Dinarello CA. Infection, fever, and exogenous and endogenous pyrogens: some concepts have changed. J Endotoxin Res 10, 201-222 (2004).

150. Li S, Wang Y, Matsumura K, Ballou LR, Morham SG, Blatteis CM. The febrile response to lipopolysaccharide is blocked in cyclooxygenase-2(-/-), but not in cyclooxygenase-1(-/-) mice. Brain Res 825, 86-94 (1999).

151. Engblom D, et al. Microsomal prostaglandin E synthase-1 is the central switch during immune-induced pyresis. Nat Neurosci 6, 1137-1138 (2003).

152. Cao C, Matsumura K, Yamagata K, Watanabe Y. Endothelial cells of the rat brain vasculature express cyclooxygenase-2 mRNA in response to systemic interleukin-1 beta: a possible site of prostaglandin synthesis responsible for fever. Brain Res 733, 263-272 (1996).

153. Matsumura K, Cao C, Ozaki M, Morii H, Nakadate K, Watanabe Y. Brain endothelial cells express cyclooxygenase-2 during lipopolysaccharide-induced fever: light and electron microscopic immunocytochemical studies. J Neurosci 18, 6279-6289 (1998).

154. Breder CD, Saper CB. Expression of inducible cyclooxygenase mRNA in the mouse brain after systemic administration of bacterial lipopolysaccharide. Brain Res 713, 64-69 (1996).

155. Schiltz JC, Sawchenko PE. Distinct brain vascular cell types manifest inducible cyclooxygenase expression as a function of the strength and nature of immune insults. J Neurosci 22, 5606-5618 (2002).

156. Cao C, Matsumura K, Yamagata K, Watanabe Y. Induction by lipopolysaccharide of cyclooxygenase-2 mRNA in rat brain; its possible role in the febrile response. Brain Res 697, 187-196 (1995).

157. Breder CD, Dewitt D, Kraig RP. Characterization of inducible cyclooxygenase in rat brain. J Comp Neurol 355, 296-315 (1995).

158. Oka T, et al. Characteristics of thermoregulatory and febrile responses in mice deficient in prostaglandin EP1 and EP3 receptors. J Physiol 551, 945-954 (2003).

159. Ek M, Engblom D, Saha S, Blomqvist A, Jakobsson PJ, Ericsson-Dahlstrand A. Inflammatory response: pathway across the blood-brain barrier. Nature 410, 430-431 (2001).

160. Ushikubi F, et al. Impaired febrile response in mice lacking the prostaglandin E receptor subtype EP3. Nature 395, 281-284 (1998).

161. Lazarus $\mathrm{M}$, et al. EP3 prostaglandin receptors in the median preoptic nucleus are critical for fever responses. Nat Neurosci, (2007).

162. Boulant JA. Role of the preoptic-anterior hypothalamus in thermoregulation and fever. Clin Infect Dis 31 Suppl 5, S157-161 (2000).

163. Blomqvist A, Engblom D. Neural Mechanisms of Inflammation-Induced Fever. Neuroscientist 24, 381399 (2018).

164. Steiner AA, et al. Cellular and molecular bases of the initiation of fever. PLoS Biol 4, e284 (2006).

165. Engstrom L, et al. Lipopolysaccharide-induced fever depends on prostaglandin E2 production specifically in brain endothelial cells. Endocrinology 153, 4849-4861 (2012). 
166. Abbott NJ, Patabendige AA, Dolman DE, Yusof SR, Begley DJ. Structure and function of the blood-brain barrier. Neurobiol Dis 37, 13-25 (2010).

167. Obermeier B, Verma A, Ransohoff RM. The blood-brain barrier. Handb Clin Neurol 133, 39-59 (2016).

168. Dejana E, Giampietro C. Vascular endothelial-cadherin and vascular stability. Curr Opin Hematol 19, 218-223 (2012).

169. Coomber BL, Stewart PA. Morphometric analysis of CNS microvascular endothelium. Microvasc Res 30, 99-115 (1985).

170. Betz AL, Goldstein GW. Polarity of the blood-brain barrier: neutral amino acid transport into isolated brain capillaries. Science 202, 225-227 (1978).

171. Keaney J, Campbell M. The dynamic blood-brain barrier. FEBS J 282, 4067-4079 (2015).

172. Armulik A, Genove G, Betsholtz C. Pericytes: developmental, physiological, and pathological perspectives, problems, and promises. Dev Cell 21, 193-215 (2011).

173. Peppiatt CM, Howarth C, Mobbs P, Attwell D. Bidirectional control of CNS capillary diameter by pericytes. Nature 443, 700-704 (2006).

174. Li $\mathrm{F}$, et al. Endothelial Smad4 maintains cerebrovascular integrity by activating $\mathrm{N}$-cadherin through cooperation with Notch. Dev Cell 20, 291-302 (2011).

175. Daneman R, Zhou L, Kebede AA, Barres BA. Pericytes are required for blood-brain barrier integrity during embryogenesis. Nature 468, 562-566 (2010).

176. Abbott NJ, Ronnback L, Hansson E. Astrocyte-endothelial interactions at the blood-brain barrier. Nat Rev Neurosci 7, 41-53 (2006).

177. Rodriguez-Arellano JJ, Parpura V, Zorec R, Verkhratsky A. Astrocytes in physiological aging and Alzheimer's disease. Neuroscience 323, 170-182 (2016).

178. Gee JR, Keller JN. Astrocytes: regulation of brain homeostasis via apolipoprotein E. Int J Biochem Cell Biol 37, 1145-1150 (2005).

179. Daneman R, Prat A. The blood-brain barrier. Cold Spring Harb Perspect Biol 7, a020412 (2015).

180. Baeten KM, Akassoglou K. Extracellular matrix and matrix receptors in blood-brain barrier formation and stroke. Dev Neurobiol 71, 1018-1039 (2011).

181. Willis CL, Garwood CJ, Ray DE. A size selective vascular barrier in the rat area postrema formed by perivascular macrophages and the extracellular matrix. Neuroscience 150, 498-509 (2007).

182. Ransohoff RM, Engelhardt B. The anatomical and cellular basis of immune surveillance in the central nervous system. Nat Rev Immunol 12, 623-635 (2012).

183. Steel CD, et al. Distinct macrophage subpopulations regulate viral encephalitis but not viral clearance in the CNS. J Neuroimmunol 226, 81-92 (2010).

184. Liu C, et al. Macrophages Mediate the Repair of Brain Vascular Rupture through Direct Physical Adhesion and Mechanical Traction. Immunity 44, 1162-1176 (2016).

185. Polfliet MM, et al. Meningeal and perivascular macrophages of the central nervous system play a protective role during bacterial meningitis. J Immunol 167, 4644-4650 (2001).

186. Siso S, Jeffrey M, Gonzalez L. Sensory circumventricular organs in health and disease. Acta Neuropathol 120, 689-705 (2010).

187. Ferguson AV. Circumventricular Organs: Integrators of Circulating Signals Controlling Hydration, Energy Balance, and Immune Function. In: Neurobiology of Body Fluid Homeostasis: Transduction and Integration (eds De Luca LA, Jr., Menani JV, Johnson AK) (2014).

188. Beeson PB. Temperature-elevating effect of a substance obtained from polymorphonuclear leucocytes. J Clin Invest 27, 524 (1948).

189. Bode JG, Ehlting C, Haussinger D. The macrophage response towards LPS and its control through the p38(MAPK)-STAT3 axis. Cell Signal 24, 1185-1194 (2012).

190. Banks WA, Ortiz L, Plotkin SR, Kastin AJ. Human interleukin (IL) 1 alpha, murine IL-1 alpha and murine IL-1 beta are transported from blood to brain in the mouse by a shared saturable mechanism. $J$ Pharmacol Exp Ther 259, 988-996 (1991).

191. Banks WA, Kastin AJ, Broadwell RD. Passage of cytokines across the blood-brain barrier. Neuroimmunomodulation 2, 241-248 (1995).

192. Banks WA. Blood-brain barrier transport of cytokines: a mechanism for neuropathology. Curr Pharm Des 11, 973-984 (2005).

193. Maness LM, Kastin AJ, Banks WA. Relative contributions of a CVO and the microvascular bed to delivery of blood-borne IL-1alpha to the brain. Am J Physiol 275, E207-212 (1998). 
194. Banks WA, Erickson MA. The blood-brain barrier and immune function and dysfunction. Neurobiol Dis 37, 26-32 (2010).

195. Ericsson A, Liu C, Hart RP, Sawchenko PE. Type-1 Interleukin-1 Receptor in the Rat-Brain - Distribution, Regulation, and Relationship to Sites of II-1-Induced Cellular Activation. J Comp Neurol 361, 681-698 (1995).

196. Vallieres L, Rivest S. Regulation of the genes encoding interleukin-6, its receptor, and gp130 in the rat brain in response to the immune activator lipopolysaccharide and the proinflammatory cytokine interleukin-1beta. J Neurochem 69, 1668-1683 (1997).

197. Konsman JP, Vigues S, Mackerlova L, Bristow A, Blomqvist A. Rat brain vascular distribution of interleukin-1 type-1 receptor immunoreactivity: relationship to patterns of inducible cyclooxygenase expression by peripheral inflammatory stimuli. J Comp Neurol 472, 113-129 (2004).

198. Blatteis CM. Role of the OVLT in the febrile response to circulating pyrogens. Prog Brain Res 91, 409412 (1992).

199. Lacroix S, Rivest S. Functional circuitry in the brain of immune-challenged rats: partial involvement of prostaglandins. J Comp Neurol 387, 307-324 (1997).

200. Blatteis CM, Bealer SL, Hunter WS, Llanosq J, Ahokas RA, Mashburn TA. Suppression of Fever after Lesions of the Anteroventral 3rd Ventricle in Guinea-Pigs. Brain Res Bull 11, 519-526 (1983).

201. Romanovsky AA, Sugimoto N, Simons CT, Hunter WS. The organum vasculosum laminae terminalis in immune-to-brain febrigenic signaling: a reappraisal of lesion experiments. Am J Physiol Regul Integr Comp Physiol 285, R420-428 (2003).

202. Klir JJ, Roth J, Szelenyi Z, McClellan JL, Kluger MJ. Role of hypothalamic interleukin-6 and tumor necrosis factor-alpha in LPS fever in rat. Am J Physiol 265, R512-517 (1993).

203. Fantuzzi G, Dinarello CA. The inflammatory response in interleukin-1 beta-deficient mice: comparison with other cytokine-related knock-out mice. J Leukoc Biol 59, 489-493 (1996).

204. Alheim K, et al. Hyperresponsive febrile reactions to interleukin (IL) 1alpha and IL-1beta, and altered brain cytokine mRNA and serum cytokine levels, in IL-1beta-deficient mice. Proc Natl Acad Sci U S A 94, 2681-2686 (1997).

205. Rummel C, Inoue W, Sachot C, Poole S, Hubschle T, Luheshi GN. Selective contribution of interleukin-6 and leptin to brain inflammatory signals induced by systemic LPS injection in mice. J Comp Neurol 511, 373-395 (2008).

206. Sehic E, Blatteis CM. Blockade of lipopolysaccharide-induced fever by subdiaphragmatic vagotomy in guinea pigs. Brain Res 726, 160-166 (1996).

207. Matsumura K, Kaihatsu S, Imai H, Terao A, Shiraki T, Kobayashi S. Cyclooxygenase in the vagal afferents: is it involved in the brain prostaglandin response evoked by lipopolysaccharide? Auton Neurosci $85,88-$ 92 (2000).

208. Romanovsky AA, Kulchitsky VA, Simons CT, Sugimoto N, Szekely M. Febrile responsiveness of vagotomized rats is suppressed even in the absence of malnutrition. Am J Physiol 273, R777-783 (1997).

209. Romanovsky AA, Simons CT, Szekely M, Kulchitsky VA. The vagus nerve in the thermoregulatory response to systemic inflammation. Am J Physiol 273, R407-413 (1997).

210. Ootsuka Y, Blessing WW, Steiner AA, Romanovsky AA. Fever response to intravenous prostaglandin E2 is mediated by the brain but does not require afferent vagal signaling. Am J Physiol Regul Integr Comp Physiol 294, R1294-1303 (2008).

211. Borovikova LV, et al. Vagus nerve stimulation attenuates the systemic inflammatory response to endotoxin. Nature 405, 458-462 (2000).

212. Nakamura K, Kaneko T, Yamashita Y, Hasegawa H, Katoh H, Negishi M. Immunohistochemical localization of prostaglandin EP3 receptor in the rat nervous system. J Comp Neurol 421, 543-569 (2000).

213. Binshtok AM, et al. Nociceptors are interleukin-1beta sensors. J Neurosci 28, 14062-14073 (2008).

214. Ross G, et al. Fever induction by localized subcutaneous inflammation in guinea pigs: the role of cytokines and prostaglandins. J Appl Physiol (1985) 94, 1395-1402 (2003).

215. Sinclair R, Eriksson AS, Gretzer C, Cassuto J, Thomsen P. Inhibitory effects of amide local anaesthetics on stimulus-induced human leukocyte metabolic activation, LTB4 release and IL-1 secretion in vitro. Acta Anaesthesiol Scand 37, 159-165 (1993).

216. Schmidt W, Schmidt H, Bauer H, Gebhard MM, Martin E. Influence of lidocaine on endotoxin-induced leukocyte-endothelial cell adhesion and macromolecular leakage in vivo. Anesthesiology 87, 617-624 (1997). 
217. Bishai I, Dinarello CA, Coceani F. Prostaglandin formation in feline cerebral microvessels: effect of endotoxin and interleukin-1. Can J Physiol Pharmacol 65, 2225-2230 (1987).

218. Moore SA, Spector AA, Hart MN. Eicosanoid metabolism in cerebromicrovascular endothelium. Am J Physiol 254, C37-44 (1988).

219. Elmquist JK, Scammell TE, Saper CB. Mechanisms of CNS response to systemic immune challenge: the febrile response. Trends Neurosci 20, 565-570 (1997).

220. Serrats J, Schiltz JC, Garcia-Bueno B, van Rooijen N, Reyes TM, Sawchenko PE. Dual roles for perivascular macrophages in immune-to-brain signaling. Neuron 65, 94-106 (2010).

221. Yamagata K, et al. Coexpression of microsomal-type prostaglandin E synthase with cyclooxygenase-2 in brain endothelial cells of rats during endotoxin-induced fever. J Neurosci 21, 2669-2677 (2001).

222. Small PM, Tauber MG, Hackbarth CJ, Sande MA. Influence of body temperature on bacterial growth rates in experimental pneumococcal meningitis in rabbits. Infect Immun 52, 484-487 (1986).

223. Rice $P$, et al. Febrile-range hyperthermia augments neutrophil accumulation and enhances lung injury in experimental gram-negative bacterial pneumonia. J Immunol 174, 3676-3685 (2005).

224. Young PJ, et al. Early peak temperature and mortality in critically ill patients with or without infection. Intensive Care Med, (2012).

225. Capacchione JF, Muldoon SM. The relationship between exertional heat illness, exertional rhabdomyolysis, and malignant hyperthermia. Anesth Analg 109, 1065-1069 (2009).

226. Lee $\mathrm{BH}$, et al. Association of body temperature and antipyretic treatments with mortality of critically ill patients with and without sepsis: multi-centered prospective observational study. Crit Care 16, R33 (2012).

227. Flower R, Gryglewski R, Herbaczynska-Cedro K, Vane JR. Effects of anti-inflammatory drugs on prostaglandin biosynthesis. Nat New Biol 238, 104-106 (1972).

228. Flower RJ, Vane JR. Inhibition of prostaglandin synthetase in brain explains the anti-pyretic activity of paracetamol (4-acetamidophenol). Nature 240, 410-411 (1972).

229. Marnett LJ, Rowlinson SW, Goodwin DC, Kalgutkar AS, Lanzo CA. Arachidonic acid oxygenation by COX1 and COX-2. Mechanisms of catalysis and inhibition. J Biol Chem 274, 22903-22906 (1999).

230. Anderson BJ. Paracetamol (Acetaminophen): mechanisms of action. Paediatr Anaesth 18, 915-921 (2008).

231. Ouellet M, Percival MD. Mechanism of acetaminophen inhibition of cyclooxygenase isoforms. Arch Biochem Biophys 387, 273-280 (2001).

232. Boutaud O, Aronoff DM, Richardson JH, Marnett L, Oates JA. Determinants of the cellular specificity of acetaminophen as an inhibitor of prostaglandin H(2) synthases. Proc Natl Acad Sci U S A 99, 7130-7135 (2002).

233. Engstrom Ruud L, et al. Acetaminophen reduces lipopolysaccharide-induced fever by inhibiting cyclooxygenase-2. Neuropharmacology 71, 124-129 (2013).

234. Cao C, Matsumura K, Yamagata K, Watanabe Y. Involvement of cyclooxygenase-2 in LPS-induced fever and regulation of its mRNA by LPS in the rat brain. Am J Physiol 272, R1712-1725 (1997).

235. Courad JP, et al. Acetaminophen distribution in the rat central nervous system. Life Sci 69, 1455-1464 (2001).

236. Kumpulainen E, Kokki H, Halonen T, Heikkinen M, Savolainen J, Laisalmi M. Paracetamol (acetaminophen) penetrates readily into the cerebrospinal fluid of children after intravenous administration. Pediatrics 119, 766-771 (2007).

237. Hinz B, Cheremina O, Brune K. Acetaminophen (paracetamol) is a selective cyclooxygenase-2 inhibitor in man. FASEB J 22, 383-390 (2008).

238. Piletta P, Porchet HC, Dayer P. Central analgesic effect of acetaminophen but not of aspirin. Clin Pharmacol Ther 49, 350-354 (1991).

239. Pickering G, Esteve V, Loriot MA, Eschalier A, Dubray C. Acetaminophen reinforces descending inhibitory pain pathways. Clin Pharmacol Ther 84, 47-51 (2008).

240. Pickering G, Loriot MA, Libert F, Eschalier A, Beaune P, Dubray C. Analgesic effect of acetaminophen in humans: first evidence of a central serotonergic mechanism. Clin Pharmacol Ther 79, 371-378 (2006).

241. Alloui A, et al. Paracetamol exerts a spinal, tropisetron-reversible, antinociceptive effect in an inflammatory pain model in rats. Eur J Pharmacol 443, 71-77 (2002).

242. Nakamura K, Li YQ, Kaneko T, Katoh H, Negishi M. Prostaglandin EP3 receptor protein in serotonin and catecholamine cell groups: a double immunofluorescence study in the rat brain. Neuroscience 103, 763 775 (2001). 
243. Bessems JG, Vermeulen NP. Paracetamol (acetaminophen)-induced toxicity: molecular and biochemical mechanisms, analogues and protective approaches. Crit Rev Toxicol 31, 55-138 (2001).

244. Hodgman MJ, Garrard AR. A review of acetaminophen poisoning. Crit Care Clin 28, 499-516 (2012).

245. James LP, Mayeux PR, Hinson JA. Acetaminophen-induced hepatotoxicity. Drug Metab Dispos 31, 14991506 (2003).

246. Hogestatt ED, et al. Conversion of acetaminophen to the bioactive N-acylphenolamine AM404 via fatty acid amide hydrolase-dependent arachidonic acid conjugation in the nervous system. J Biol Chem 280, 31405-31412 (2005).

247. Ottani A, Leone S, Sandrini M, Ferrari A, Bertolini A. The analgesic activity of paracetamol is prevented by the blockade of cannabinoid CB1 receptors. Eur J Pharmacol 531, 280-281 (2006).

248. Mechoulam R, Parker LA. The endocannabinoid system and the brain. Annu Rev Psychol 64, 21-47 (2013).

249. Zygmunt PM, Chuang H, Movahed P, Julius D, Hogestatt ED. The anandamide transport inhibitor AM404 activates vanilloid receptors. Eur J Pharmacol 396, 39-42 (2000).

250. Tominaga $\mathrm{M}$, et al. The cloned capsaicin receptor integrates multiple pain-producing stimuli. Neuron 21, 531-543 (1998).

251. Mallet C, et al. TRPV1 in brain is involved in acetaminophen-induced antinociception. PLoS One 5, (2010).

252. Andersson DA, et al. TRPA1 mediates spinal antinociception induced by acetaminophen and the cannabinoid Delta(9)-tetrahydrocannabiorcol. Nat Commun 2, 551 (2011).

253. Walker RM, Massey TE, McElligott TF, Racz WJ. Acetaminophen-induced hypothermia, hepatic congestion, and modification by N-acetylcysteine in mice. Toxicol Appl Pharmacol 59, 500-507 (1981).

254. Gentry C, Andersson DA, Bevan S. TRPA1 mediates the hypothermic action of acetaminophen. Sci Rep 5, 12771 (2015).

255. Lander ES, et al. Initial sequencing and analysis of the human genome. Nature 409, 860-921 (2001).

256. Mouse Genome Sequencing C, et al. Initial sequencing and comparative analysis of the mouse genome. Nature 420, 520-562 (2002).

257. Thomas KR, Capecchi MR. Site-Directed Mutagenesis by Gene Targeting in Mouse Embryo-Derived Stem-Cells. Cell 51, 503-512 (1987).

258. Mansour SL, Thomas KR, Capecchi MR. Disruption of the proto-oncogene int-2 in mouse embryoderived stem cells: a general strategy for targeting mutations to non-selectable genes. Nature 336, 348352 (1988).

259. Sternberg N, Hamilton D. Bacteriophage P1 site-specific recombination. I. Recombination between loxP sites. J Mol Biol 150, 467-486 (1981).

260. Metzger D, Clifford J, Chiba H, Chambon P. Conditional site-specific recombination in mammalian cells using a ligand-dependent chimeric Cre recombinase. Proc Natl Acad Sci U S A 92, 6991-6995 (1995).

261. Saper CB, Romanovsky AA, Scammell TE. Neural circuitry engaged by prostaglandins during the sickness syndrome. Nat Neurosci 15, 1088-1095 (2012).

262. Eskilsson A, Tachikawa M, Hosoya K, Blomqvist A. Distribution of microsomal prostaglandin E synthase1 in the mouse brain. J Comp Neurol 522, 3229-3244 (2014).

263. Ishikawa TO, Herschman HR. Conditional knockout mouse for tissue-specific disruption of the cyclooxygenase-2 (Cox-2) gene. Genesis 44, 143-149 (2006).

264. Ridder DA, et al. TAK1 in brain endothelial cells mediates fever and lethargy. J Exp Med 208, 2615-2623 (2011).

265. Ching S, et al. Endothelial-specific knockdown of interleukin-1 (IL-1) type 1 receptor differentially alters CNS responses to IL-1 depending on its route of administration. J Neurosci 27, 10476-10486 (2007).

266. Li S, Ballou LR, Morham SG, Blatteis CM. Cyclooxygenase-2 mediates the febrile response of mice to interleukin-1beta. Brain Res 910, 163-173 (2001).

267. Reyes TM, Walker JR, DeCino C, Hogenesch JB, Sawchenko PE. Categorically distinct acute stressors elicit dissimilar transcriptional profiles in the paraventricular nucleus of the hypothalamus. $J$ Neurosci 23, 5607-5616 (2003).

268. Rummel C, Sachot C, Poole S, Luheshi GN. Circulating interleukin-6 induces fever through a STAT3-linked activation of COX-2 in the brain. Am J Physiol Regul Integr Comp Physiol 291, R1316-1326 (2006).

269. Gadient RA, Otten U. Postnatal expression of interleukin-6 (IL-6) and IL-6 receptor (IL-6R) mRNAs in rat sympathetic and sensory ganglia. Brain Res 724, 41-46 (1996). 
270. Wang J, Ando T, Dunn AJ. Effect of homologous interleukin-1, interleukin-6 and tumor necrosis factoralpha on the core body temperature of mice. Neuroimmunomodulation 4, 230-236 (1997).

271. Cartmell T, Poole S, Turnbull AV, Rothwell NJ, Luheshi GN. Circulating interleukin-6 mediates the febrile response to localised inflammation in rats. J Physiol 526 Pt 3, 653-661 (2000).

272. Elander L, et al. Inducible prostaglandin E2 synthesis interacts in a temporally supplementary sequence with constitutive prostaglandin-synthesizing enzymes in creating the hypothalamic-pituitary-adrenal axis response to immune challenge. J Neurosci 29, 1404-1413 (2009).

273. Rose-John S. IL-6 trans-signaling via the soluble IL-6 receptor: importance for the pro-inflammatory activities of IL-6. Int J Biol Sci 8, 1237-1247 (2012).

274. Rose-John S, Heinrich PC. Soluble receptors for cytokines and growth factors: generation and biological function. Biochem J 300 ( Pt 2), 281-290 (1994).

275. LeMay LG, Vander AJ, Kluger MJ. Role of interleukin 6 in fever in rats. Am J Physiol 258, R798-803 (1990).

276. Li S, Dou W, Tang Y, Goorha S, Ballou LR, Blatteis CM. Acetaminophen: antipyretic or hypothermic in mice? In either case, PGHS-1b (COX-3) is irrelevant. Prostaglandins Other Lipid Mediat 85, 89-99 (2008).

277. Atkuri KR, Mantovani JJ, Herzenberg LA, Herzenberg LA. N-Acetylcysteine--a safe antidote for cysteine/glutathione deficiency. Curr Opin Pharmacol 7, 355-359 (2007).

278. Doherty NS, Beaver TH, Chan KY, Dinerstein RJ, Diekema KA. The antinociceptive activity of paracetamol in zymosan-induced peritonitis in mice: the role of prostacyclin and reactive oxygen species. $\mathrm{Br} J$ Pharmacol 101, 869-874 (1990).

279. Meseguer V, et al. TRPA1 channels mediate acute neurogenic inflammation and pain produced by bacterial endotoxins. Nat Commun 5, 3125 (2014).

280. Bar-Or D, Bar-Or R, Rael LT, Brody EN. Oxidative stress in severe acute illness. Redox Biol 4, 340-345 (2015).

281. Feldberg W, Gupta KP. Pyrogen fever and prostaglandin-like activity in cerebrospinal fluid. J Physio/ 228, 41-53 (1973).

282. Warner TD, Vojnovic I, Giuliano F, Jimenez R, Bishop-Bailey D, Mitchell JA. Cyclooxygenases 1, 2, and 3 and the production of prostaglandin 12: investigating the activities of acetaminophen and cyclooxygenase-2-selective inhibitors in rat tissues. J Pharmacol Exp Ther 310, 642-647 (2004).

283. Ayoub SS, Botting RM, Goorha S, Colville-Nash PR, Willoughby DA, Ballou LR. Acetaminophen-induced hypothermia in mice is mediated by a prostaglandin endoperoxide synthase 1 gene-derived protein. Proc Natl Acad Sci U S A 101, 11165-11169 (2004).

284. Ayoub SS, Colville-Nash PR, Willoughby DA, Botting RM. The involvement of a cyclooxygenase 1 genederived protein in the antinociceptive action of paracetamol in mice. Eur J Pharmaco/ 538, 57-65 (2006). 


\section{Papers}

The papers associated with this thesis have been removed for copyright reasons. For more details about these see:

http://urn.kb.se/resolve?urn=urn:nbn:se:liu:diva-168711 


\section{FACULTY OF MEDICINE AND HEALTH SCIENCES}

Linköping University Medical Dissertation No. 1750, 2020

Department of Biomedical and Clinical Sciences

Linköping University

SE-581 83 Linköping, Sweden

www.liu.se 